
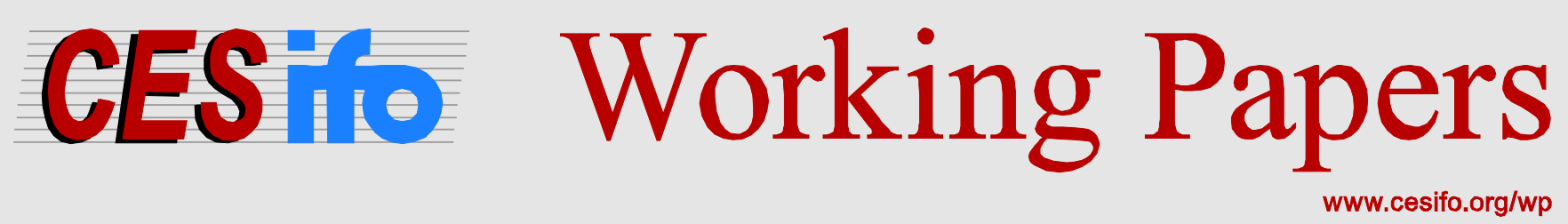

\title{
Repeated Lobbying by Commercial Lobbyists and Special Interests
}

\author{
Thomas Groll \\ Christopher J. Ellis
}
CESIFO WORKING PAPER NO. 5809
CATEgORY 2: PUBliC CHOICE
MARCH 2016
An electronic version of the paper may be downloaded
- from the SSRN website:
- from the RePEc website:
- from the CESifo website:
wWw.SSRN.com
Www.RePEc.org
www.CESifo-group.org/wp




\title{
Repeated Lobbying by Commercial Lobbyists and Special Interests
}

\begin{abstract}
Using a model of repeated agency, we explain previously unexplained features of the real-world lobbying industry. Lobbying is divided between direct representation by special interests to policymakers, and indirect representation where special interests employ professional intermediaries called commercial lobbyists to lobby policymakers on their behalf. Our analytical structure allows us to explain several trends in lobbying. For example, using the observation that in the U.S. over the last 20 years policymakers have spent an increasing amount of their time fundraising as opposed to legislating, we are able to explain why the share of commercial lobbyist activity in total lobbying has risen dramatically and now constitutes over $60 \%$ of the total. The key scarce resource in our analysis is policymakers' time. They allocate this resource via implicit repeated agency contracts which are used to incent special interests and commercial lobbyists to provide a mix of financial contributions and information on policy proposals. These implicit agency contracts solve both an information problem in the presence of unverifiable policy information and a contracting problem in the absence of legal enforcement. These repeated relationship, that are often described using the pejorative term cronyism in the popular press, may in certain circumstances be welfare improving.
\end{abstract}

JEL-Codes: D720, D780, D830, H110, P160.

Keywords: lobbying, political access, intermediaries, information acquisition, financial contributions.

\author{
Thomas Groll \\ Comumbia University \\ School of International \& Public Affairs \\ USA - New York, NY \\ tgroll@columbia.edu
}

\author{
Christopher J. Ellis \\ University of Oregon \\ Department of Economics \\ USA - Eugene, OR \\ cjellis@uoregon.edu
}

\footnotetext{
March 2016

We thank David-Austen Smith, Shankha Chakraborty, Christopher Cotton, Arnaud Dellis, John Duggan, Martin Gregor, Ross Hickey, Matias Iaryczower, Jenni Jaakkola, Lawrence Lessig, Suresh Naidu, Andrea Prat, Nicholas Sly, and Francesco Trebbi for discussions and suggestions. The work benefited from the comments of seminar participants at Clemson University, Columbia University, George Mason University, Harvard University (E.J. Safra Center for Ethics), Illinois State University, University of Birmingham, and University of Oregon as well as participants at the 2012 APET Workshop on Governance and Political Economy, 2013 APET meeting, 2013 CEPET workshop, 2013 Silvaplana workshop, and 2013 CPEG meeting. An earlier version was circulated under the title "Dynamic Commercial Lobbying”. All errors are our own.
} 


\section{Introduction}

In recent policy debates on both sides of the Atlantic much concern has been expressed over the influence of lobbyists on the political process. ${ }^{1}$ Clearly there are social costs and benefits associated with lobbying. ${ }^{2}$ The transmission of policy relevant information can potentially improve political decision-making, whereas the transfer of resources so as to purchase influence seems to be largely distortionary. ${ }^{3}$ This may explain why the public continues to tolerate lobbying activities yet increasingly demands that they be regulated. ${ }^{4}$

The preexisting literature throws considerable light on the direct activities of special interest groups in the lobbying process. However, the dominant models in the literature cannot explain why the preponderance of lobbying in the United States and much lobbying in Europe is not done directly by special interests but rather is performed by professional for-profit intermediaries known as commercial lobbyists. ${ }^{5}$ Figure 1 illustrates the importance and growth in commercial lobbying.

The data in Figure 1 also demonstrate that the share of commercial lobbyists amongst all lobbyists active at the U.S. federal level has been increasing since 2000, and that they are the predominant type. ${ }^{6}$ Furthermore, the growth in total lobbying expenditures in the last decade is almost entirely accounted for by the increase in commercial lobbying activities. The role of internal lobbyists seems primarily to one of monitoring the political process. Once they have detected the need for influence activities, then commercial lobbyists, the so called "hired guns", are employed. ${ }^{7}$

Neither the menu auction nor cheap talk models of lobbying found in the literature can capture the key features of the recent changes in the lobbying industry. These involve repeated interactions

\footnotetext{
${ }^{1}$ Lobbying is a phenomenon in all democratic countries. The New York Times' online service "Topics" provides a special archive for articles related to lobbying and lobbyists, and the Washingtonian publishes a list of the 50 top lobbyists (Eisler, 2007). The extensive Dodd-Frank Wall Street Reform Act and the process of its drafting caused a windfall of lobbying revenues, especially for lobbyists with expertise in financial products and regulation (Becker, 2010). The British House of Commons Public Administration Select Committee (2009) took the observed activities by commercial lobbying as reason to analyze current lobbying activities and regulation in the United Kingdom. The European Parliament and the European Commission responded to public pressure and started lobbyist registrars.

${ }^{2}$ The welfare implications of lobbying activities depend on the provision of policy relevant information relative to the risk of political capture: "[...] for the disclosure of efforts by paid lobbyists to influence the decision-making process and actions of the Federal legislative and executive branch officials while protecting the constitutional right of the people to petition the government for a redress of their grievances." The Lobbying Disclosure Act (LDA), 1995 - Purpose and Summary.

${ }^{3}$ Common resource transfers include the supply of research reports, legislative drafts, grass roots organization, staff, campaign contributions, networking events, gifts, and career opportunities (the notorious "revolving door").

${ }^{4}$ See Chari, Hogan, and Murphy (2010) for an institutional comparison across countries.

${ }^{5}$ For an introduction and review of special interests see Olson (1965), Persson and Tabellini (2000), Grossman and Helpman (2001) and Congleton, Hillman and Konrad (2008). Hall and Deardorff (2006) review various lobbying theories.

${ }^{6}$ Data from Bertrand, Bombardini and Trebbi (2014).

${ }^{7}$ For example, Nownes (2013) reports that more than 40 percent of lobbyists' total work time is spent on monitoring government, researching government proposals, and monitoring other interest groups and lobbyists.
} 


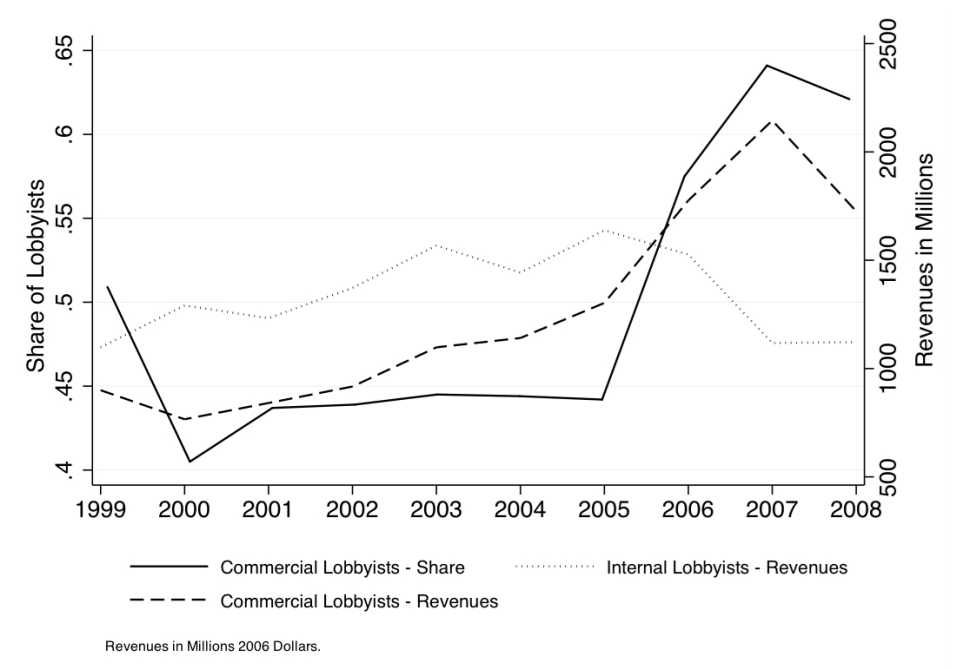

Figure 1: Recent Developments in U.S. Federal Lobbying.

between policymakers and commercial lobbyists in a world of asymmetric information. Our approach will be to construct a simple general equilibrium model in which we nest the detailed features of the commercial lobbying industry in an appropriate institutional environment. Our contribution is to provide a theoretical explanation for recent reduced form empirical results and to identify the sources of distortions that are likely present in reality. As such our contribution is also to inform policy. To this end we first describe some of the features of the commercial lobbying industry and the institutional and economic environment in which commercial lobbying firms operate. Table 1 provides some summary statistics for commercial lobbyists operating in the United States.

The data in Table 1 reveal several interesting features of the lobbying industry. ${ }^{8}$ The first observation is its size; this is a billion dollar industry with total revenues that exceed annual campaign contributions. ${ }^{9}$ If we consider that this in part describes the revenues spent by the industry's clients so as to ascertain how to spend their other "influence dollars", it may be hard to underestimate its importance. The second observation is that the numbers for Alumni Lobbyists and Current Congress Members Served are much lower than might be anticipated. An Alumni Lobbyist is an employee of a lobbying firm that previously served on the staff of a current Congress member. Current Congress Members Served is the total number of current Congress members for whom the employees of a lobbying firm have been staffers. While far from exhausting all the possible avenues of contact between lobbying firms and policymakers, these numbers suggest that lobbying firms may do rather

\footnotetext{
${ }^{8}$ Data are from Lobbyists.info: "Factors of Influence", updated Feb 5 2013, Aug 14 2013. Data are for second semester 2012 and first semester 2013. The LDA specifies 79 issue codes such as, Accounting, Advertising, Health Issues, Tobacco, or Tourism. In the Supplemental Appendix we provide similar descriptive statistics for 2010.

${ }^{9}$ De Figueiredo and Richter (2014) estimate that lobbying expenditures are approximately five times those of interest groups' campaign contributions.
} 
Table 1: Summary Statistics Lobbying Firms - U.S. Federal Lobbying 2012/13

\begin{tabular}{lccccc}
\hline \multicolumn{1}{c}{ Variable } & Mean & Std. Dev. & Min. & Max. & Median \\
\hline Number of Employees & 6.459 & 18.278 & 1 & 239 & 2 \\
$\quad$ In DC-Area & 5.653 & 17.648 & 0 & 236 & 1 \\
$\quad$ Outside DC-Area & 0.806 & 2.856 & 0 & 56 & 0 \\
Clients & 9.197 & 17.571 & 1 & 225 & 4 \\
Issue Categories & 5.611 & 7.608 & 0 & 58 & 3 \\
Revenues in Current $\$ 1,000$ & 755.226 & 2063.591 & 5 & 29,700 & 180 \\
Alumni Lobbyists & 0.474 & 1.254 & 0 & 16 & 0 \\
Current Congress Members Served & 0.55 & 1.5 & 0 & 18 & 0 \\
N=1554 & & & & & \\
\hline
\end{tabular}

more than make introductions between their clients and their policymaker contacts. A final suggestive observation is that a typical lobbying firm only lobbies on 5.611 issues out of the 79 issue codes in a given year and services approximately twice as many clients as issue categories, suggesting that they engage in a degree of specialization. ${ }^{10}$ We incorporate these features together with an emphasis on repeated interactions between policymakers, special interests and lobbyists. This reflects the findings of the recent empirical literature that stresses the importance of ongoing relationships. ${ }^{11}$

In what follows we model lobbying as a repeated game between these for-profit commercial lobbyists and policymakers. This game is then nested in a simple general equilibrium framework. Our approach contrasts with much of the work on special interest group lobbying, since we argue that commercial lobbyists differ from the "biased experts" and "advocates" found in that literature. A commercial lobbyist is like a biased expert in that they possess a technology that allows them to improve the information available about the quality of policies, however they are not directly affected by implemented policies. ${ }^{12}$ Furthermore, a commercial lobbyist is also like an advocate as

\footnotetext{
${ }^{10}$ Notice that for the largest firms the ratio of clients to issues rises to approximately 4:1 suggesting that the few issues lobbied over by a typical firm may not be simply a matter of small firm size. Bertrand, Bombardini, and Trebbi (2014) analyze whether lobbyists provide issue expertise to policymakers or offer political access to potential clients. They show that the value of a lobbyist mostly derives from their political access rather than their expertise. Further, they show that commercial lobbyists are more specialized with respect to issue expertise than in-house lobbyists.

${ }^{11}$ Recent empirical work by Blanes i Vidal, Draca and Fons-Rosen (2012) focuses on the importance of personal relationships between lobbyists and policymakers by analyzing the "revolving door" phenomenon in which politicians and staff members become lobbyists during their careers and share previous work experiences. Bertrand, Bombardini, and Trebbi (2014) show that lobbyists, measured by campaign donations and reported policy issues, follow their political contacts and change their political work issues when those contacts change offices or committee assignments and political issues. Kerr, Lincoln, and Mishra (2013) focus on lobbying activities by corporations and show there is persistence in the set of corporations involved in lobbying on immigration. Empirical work by Krozner and Stratmann (1998) argues that the committee system in Congress provides an environment that facilitates repeated interactions and reputation building between special interest groups and politicians. The committee structure and repeated interactions create informal agreements of legislative support in return for campaign contributions in the absence of legal contracts.

${ }^{12}$ For example, Crawford and Sobel (1982), Gilligan and Krehbiel (1989), Austen-Smith (1994), and Krishna and Morgan (2001) study the behavior of a single or multiple experts with private information who advise an imperfectly informed decision-maker. The latter show that a decision-maker may want to consult competing biased experts to gain valuable information. In contrast, commercial lobbyists are not directly affected by the policy itself.
} 
they represent their clients' interests to a policymaker. ${ }^{13}$ A biased expert has a direct incentive to misrepresent private information to a policymaker, whereas an advocate may be induced by a client to do this. A commercial lobbyist is somewhat different, they are the de facto agents of policymakers who incent them to supply information of a given endogenous quality. Meeting these informational requirements has reputational effects which in turn affect their profitable future access to policymakers. They have no inherent policy bias, and are not incented to do so by clients. ${ }^{14}$

Our simple general equilibrium model is populated by three types of infinitely lived agents, citizens (who may also be regarded as special interest groups), commercial lobbyists and policymakers. There is a fixed number of total agents in the economy of which a given number are designated as policymakers by a constitution, the remainder may be either citizens or commercial lobbyists. In every period each citizen is endowed with a policy proposal which if enacted by a policymaker yields the citizen a private benefit and generates a social spillover, which can be either positive or negative. Each commercial lobbyist is endowed with some expertise that allows them to observe a signal correlated with the sign of the social spillover. Every policymaker has a per period time endowment that allows them to enact a limited number of policies. Output in this economy is simply the sum of realized private benefits plus social spillovers. There are three markets. Firstly, a market for political intermediation in which citizens pay a market clearing fee to commercial lobbyists to present their policy proposals to policymakers. Secondly, a market for political access in which policymakers design access rules that allocate their time to policies. Finally, a labor market in which the division of individuals between the roles of citizen and lobbyist is determined by entry barriers into the lobbying industry. These barriers arise from the policymakers' optimal access rules on the political access market. ${ }^{15}$ These access rules take the form of repeated agency contracts. This structure is adopted for three reasons, firstly, it incorporates the institutional features found to be important in the empirical literature, secondly, it fits well the features of the industry as described in Table 1 above, and, finally, it corresponds to information obtained in interviews with professional lobbyists. ${ }^{16}$

\footnotetext{
${ }^{13}$ Dewatriport and Tirole (1999) point out that decision-based rewards are determined by the advocate's achievements for the client, whereas information-based rewards are based on how outcomes were achieved. Their analysis focuses on decision-based rewards and shows that informational benefits for a decision-maker are maximized when there are multiple advocates each incented by their own clients. In contrast, commercial lobbyists represent many clients and compete for scarce political access, which implies that citizens fund lobbying but policymakers incent lobbyists.

${ }^{14}$ Currently ongoing work by Hirsch and Montagnes (2015) considers the ideological alignments of an individual lobbyist and a single policymaker. As in our analysis a lobbyist for hire gains from her credibility and reputation. In their analysis a lobbyist faces a trade-off between representing ideologically aligned or ideologically unaligned clients.

${ }^{15}$ We show that policymakers announce political access rules that reward commercial lobbyists' current lobbying effort with future political access. The scarcity of political access and the policymakers' need to incent lobbyists for their unobservable effort create barriers to entry for citizens into the lobbying industry.

${ }^{16}$ In one of the interviews with the authors a professional lobbyist stated that access to policymakers is obtained by working through intermediaries that already enjoy an ongoing relationship, but that continued access required the
} 
This framework allows us to make a number of contributions. Firstly, we are the first to articulate why commercial lobbying firms coexist with special interest groups, and to offer explanations for the recent substantial changes in the size and composition of this industry. In our analysis there are four potential equilibria, characterized by whether lobbying is performed by commercial lobbyists, citizens, or both, and by what they deliver to the policymaker, in terms of information and financial contributions, in return for political access. The recent growth in commercial lobbying can be explained by the reduction in the time policymakers have to listen to policy proposals. In our analysis commercial lobbyists, who represent multiple clients, enjoy scale economies that make them more efficient than citizens in terms of the time it costs a policymaker to receive given levels of information and contributions. As policymakers' time available for legislative activities has become scarcer due to increasing demands to engage in fundraising, then this margin has become more important and they have increasingly turned to commercial lobbyists to supply information and contributions.

Secondly, we are able to understand the repeated agency contracts, designed by policymakers in a world of asymmetric information. Policymakers want financial contributions and policy relevant information. They need to ensure that promised financial contributions are actually delivered (at election times perhaps) and that the information they receive is of the requisite quality. We term these the contracting and information problems, both of which may be solved via repeated agency contracts. These repeated interactions are not explained elsewhere in the literature. Policymakers' information and contracting problems provide an explicit explanation for the observed repeated interactions between policymakers, special interests and lobbyists. A feature that is absent in other lobbying models. Thirdly, we show that these repeated agency contracts, which may appear to involve cronyism, can in fact be socially desirable. Finally, by comparing the market outcome to the full information welfare optimum we are able to carefully identify the distortions introduced by the existence of commercial lobbying and their welfare implications.

Our analysis illustrates how lobbyists subsidize resource constrained policymakers (Hall and Deardorff 2006) and captures that access to policymakers is the key resource in lobbying (Hansen 1991; i Vidal, Draca and Fons-Rosen 2012; Bertrand, Bombardini and Trebbi 2014). ${ }^{17}$ We show how both of these elements drive the observed personal relationships between lobbyists and policymakers and how there is a change in the composition of lobbying and its earned revenues. Furthermore, we show that lobbying rents are not fully dissipated, which is consistent with the empirical lobbying literature (de

delivery of useful, quality information.

${ }^{17}$ Similarly, Hall and Wayman (1990), Hojnacki and Kimball (2001), Baumgartner, Berry, Hojnacki, Kimball, and Leech (2009) use interviews with lobbyists to document strategies in gaining limited access. 
Figueiredo and Richter 2014), and explain with informational rents for lobbyists and not internalized policy spillovers.

Our study is also related to the lobbying literature that focuses on the provision of campaign contributions and information. In one stream of this literature, special interest groups use financial contributions to gain limited access to a policymaker, which then allows them to present either unverifiable or verifiable information such that contributions and information are complements (Lohmann 1995; Austen-Smith 1995, 1998; Cotton 2009, 2012). In another stream, special interest groups already have access, but realize that their informational searches may not yield the desired results and that financial contributions serve as a less risky substitute (Bennedsen and Feldmann 2006; Dahm and Porteiro 2008). In our analysis, lobbyists simultaneously provide both information and financial contributions which are substitutes at the margin. Access requires that they provide the requisite portfolio of these elements. ${ }^{18}$ Our current analysis adds to work by Groll and Ellis (2014). Firstly, here we endogenously determine the allocation of political access between commercial lobbyists and special interests. Secondly, we introduce two key moral hazard problems. The first involves the inability of policymakers and lobbyists or special interests to contract over financial contributions. The second involves the unobservability of the lobbyists verification activities. These elements are essential for explaining observed repeated interactions between lobbyists, special interests and policymakers as well as the composition of lobbying activities. Thirdly, we endogenously determine the mix of lobbying activities in terms of information transmission and supplying financial contributions for both commercial lobbyists and special interests. Finally, we are to able the explain the size and profitability of the commercial lobbying industry.

The rest of this paper is organized as follows: Section 2 presents the model and political access rules. Section 3 characterizes the steady state general equilibrium. Section 4 analyzes the social desirability of the equilibrium. Section 5 concludes and discusses the findings. ${ }^{19}$

\section{The Model}

The society studied consists of $C$ citizens, $L$ lobbyists, and $P$ policymakers, indexed by $c, l$ and $p$ respectively, and where $T=C+L+P$ is the total population. All agents are self-interested,

\footnotetext{
${ }^{18}$ For lobbying models that examine financial contributions see for example Bernheim and Whinston (1986), Grossman and Helpman (1994, 1996), Besley and Coate (2001); for lobbying models that focus on information provision see for example Crawford and Sobel (1982), Gilligan and Krehbiel (1989), Potters and van Winden (1992), Austen-Smith (1994), and Bennedsen and Feldmann (2002).

${ }^{19}$ Further derivations and proofs may be found in the Appendix. Full details to the corner solutions are in the Supplemental Appendix.
} 
risk-neutral, and infinitely lived. Each citizen in each period $t$ receives a single policy proposal that if enacted yields a private benefit of $\pi^{c}>0$ and creates a symmetric social spillover of $s_{t}^{c}$ that can be either positive or negative. ${ }^{20}$ A policy proposal with a positive spillover is socially desirable whereas one with a negative spillover is not - i.e., $\pi^{c}+s_{t}^{c} \gtrless 0$ as $s_{t}^{c} \gtrless 0$. The signs of spillovers are unknown to society in $t$, but are observed in $t+1$. However, all members of society know the exogenous probabilities of the spillovers which we write as $\rho\left(s^{+}\right)=\operatorname{Pr}\left(s_{t}^{c}>0\right)$ and $\rho\left(s^{-}\right)=\operatorname{Pr}\left(s_{t}^{c}<0\right)$. Ex ante the expected social value of any policy proposal is positive - i.e., $\pi_{c}+s_{t}^{c}\left[\rho\left(s^{+}\right)-\rho\left(s^{-}\right)\right]>0$.

A policy proposal can be presented to a policymaker for enactment either directly by the citizen or indirectly via a lobbyist. Lobbyists posses technical expertise, which we refer to as a verification technology and which allows them to receive signals correlated with the signs of the spillovers associated with the policy proposals they receive from citizen-clients. It then follows that lobbyists may determine the expected informational quality of proposals presented to a policymaker by choosing the proportions of proposals that are unverified and verified, and the proportions of verified proposals that received positive or negative verification signals. We refer to a combination of proposals of given expected informational quality together with financial contributions as the portfolio which is passed from lobbyists to policymakers.

Each policymaker has a per period time constraint, which limits the number of enacted policies, and no independent verification technology. The allocation of their time is determined by political access rules, $\tilde{a}^{c p}($.$) and \tilde{a}^{l p}($.$) , which specify for individual citizens and lobbyists respectively the$ portfolios they must deliver to receive a given amount of access. All policy proposals presented to policymakers are enacted and their private benefits and social spillovers are realized. In this sense, policymakers act only as "gatekeepers" whose role is to decide how to allocate their scarce time by choosing which agents' proposals to listen to.

The timing of the model for each period $t$ is: First, nature determines the signs of the spillovers for each policy proposal. Second, all policymakers simultaneously announce individual access rules to citizens and lobbyists. Third, citizens choose, when feasible, whether to become a lobbyist or continue as a citizen with a policy proposal. Fourth, lobbyists accept a certain number of proposals from clients and may investigate some of them. Finally, lobbyists present to policymakers a portfolio of promised financial contributions and policy proposals, which are then enacted and their associated benefits and spillovers are realized.

\footnotetext{
${ }^{20}$ Policy spillovers can be given several interpretations such as an externality or impure public good. Our treatment of spillovers is simple and symmetric so as to focus attention on the role of repeated interactions.
} 
The information structure is as follows. The actions by lobbyists, and the interactions between lobbyists and policymakers are unobservable for citizens. However, citizens can observe the amount of political access, $\tilde{a}_{t}^{l p}$, and the number of clients, $n_{t}^{l}$, of each lobbyist. Policymakers know the characteristics of the lobbyists' verification technology but cannot observe the lobbyists' efforts and received verification signals in $t$. Furthermore, promised financial contributions are not delivered until after lobbyists have received access. However, each policymaker observes in $t+1$ whether the promises of financial contributions made were honored, and the previous period's realized spillovers. All individuals know the proportion of citizens, lobbyists and policymakers in the population in $t$, where the latter is determined by a commonly known constitutional rule with $P_{t}=\bar{P}$.

There are three markets in the economy; a market for professional lobbying services in which citizens and lobbyists trade intermediation services, a market for political access in which lobbyists and citizens transact with policymakers over the policymakers' scarce time, and a labor market in which individuals are allocated between the roles of citizen or lobbyist. ${ }^{21}$ The market for intermediation is assumed to be perfectly competitive with a market clearing service fee of $k_{t}$. The market for political access is cleared via equilibrium implicit agency contracts between policymakers and lobbyists. These agency contracts take the form of access rules that reward financial contributions and information quality with future political access. The agency rules in the market for political access create barriers to entry that yield lobbyists information rents, this implies that in the labor market citizens would choose to become lobbyists if they could. However, limited access to policymakers prevents them from doing so. We begin by describing the choices and associated payoffs for each of the agent types.

\subsection{Citizens}

Each citizen first chooses whether to attempt to become a lobbyist. This choice depends on the expected lifetime payoffs from selecting one of the two roles in the current period, which we write as $V_{t}^{c}$ and $V_{t}^{l}$. The terms $V_{t}^{c}$ and $V_{t}^{l}$ involve the per period payoffs in the states citizen and lobbyist and the transition probabilities between these states, all of which we shall make precise shortly.

In periods when an individual chooses to be a citizen they must decide how to use their policy proposal. A proposal if enacted realizes the private benefit of $\pi^{c}$ and generates a social spillover. Each citizen, together with all other agents, shares equally in the sum of realized spillovers, $S_{t}=\sum_{c=1}^{A_{t}} s_{t}^{c}$, where $A_{t}$ is the number of enacted policies in period t. Citizens may present their proposals to

\footnotetext{
${ }^{21}$ Our market structure is consistent with Bertrand, Bombardini, and Trebbi (2014) who provide empirical support that political access rather than expertise is the scarce resource and hence we allow for free access in the market for intermediation services but employ agency contracts in the market for political access.
} 
a policymaker or hire a commercial lobbyist to present the proposal on their behalf for a fee of $k_{t}{ }^{22,23} \mathrm{~A}$ citizen can hire only one lobbyist in $t$. If the citizen presents her proposal directly, the policymaker may expect a financial contribution. The citizen promises a financial contribution of $f_{t}^{c p}$ to policymaker $p$ in $t$, this is private information in the current period but observable in $t+1$. If a policy proposal is not enacted, it expires at the end of the period and is replaced by a new draw.

The payoff for citizen $c$ in $t$ is then:

$$
\Pi_{t}^{c}=v \pi^{c}-y k_{t}-z f_{t}^{c p}+\frac{S_{t}}{T}
$$

where $y$ and $z$ are indicator variables such that $v, y, z \in\{0,1\}$ and $y \neq z$. If a citizen's proposal is enacted, then $v=1$; if they hire a lobbyist, then $y=1$; and if they make a financial contribution to a policymaker, then $z=1$. We assume that there are enough citizens such that they treat aggregate spillovers as parametric; hence, their choices involve only their private payoffs determined by $v, y$, and $z$. We assume for simplicity that citizens have no independent information verification technology. ${ }^{24}$

\subsubsection{Demand for Direct Access and Intermediation}

In choosing between making a direct approach to a policymaker, working through a commercial lobbyist as an intermediary, or being inactive a citizen needs to compute the expected payoffs of these alternatives. The citizens' payoff from direct political access is given by

$$
\pi^{c}-z f_{t}^{c p} \text { for all } t
$$

if access is granted by a policymaker in exchange for a potential contribution. Otherwise the citizen's expected payoff follows from being inactive or hiring a lobbying firm.

The citizen's alternative is to hire a lobbyist to present the policy proposal. They cannot observe the behind-closed-doors interactions between lobbyists and policymakers, but can use information on the lobbyist's political access, $\tilde{a}_{t}^{l p}$, and the number of clients, $n_{t}^{l}$, to form an expectation that their proposal will be presented by $l$. The expected payoff from hiring a lobbyist depends on the likelihood

\footnotetext{
${ }^{22}$ We observe that lobbyists and clients agree to formal contracts. However, "lobbying success fees" are widely illegal - see the Center for Ethics in Government (2010). We also observe that commercial lobbyists consult both policymakers and clients by informing their clients about the likelihood of success in a current political environment.

${ }^{23}$ We shall frequently refer to citizens that present their proposals directly to policymakers as citizen-donors, while those that employ commercial lobbyists as intermediaries are referred to as citizen-clients. Further, as appropriate to the context, we shall use the equivalent terms citizen-donor and special interest group interchangeably.

${ }^{24}$ We base this assumption on the observation that commercial lobbying firms possess specialized expertise in legal and public affairs giving them an advantage over citizens in information gathering and verification. This assumption streamlines the analysis without any significant qualitative implications.
} 
the proposal will be presented to a policymaker, the private benefit of the policy proposal, and the lobbying service fee. Hence, then expected payoff from employing a lobbyist is given by

$$
\frac{\tilde{a}_{t}^{l p}}{n_{t}^{l}} \pi^{c}-k_{t} .
$$

Finally, a citizen has the alternative of being politically inactive, which yields a certain private benefit of zero. The citizens' individual demand for commercial lobbying services is now defined by

$$
\frac{\tilde{a}_{t}^{l p}}{n_{t}^{l}} \pi^{c}-k_{t} \geq \max \left\{\pi^{c}-f_{t}^{c p}, 0\right\}
$$

where the right-hand side is zero if a citizen expects no direct political access.

\subsection{Lobbying Firms}

Each citizen that chooses to become a lobbyist constitutes an independent profit-maximizing lobbying firm that provides an intermediation service between citizens and policymakers. ${ }^{25}$ A lobbyist accepts proposals from citizen-clients and receives access from policymakers for the presentation of some proposals. They charge their $n_{t}^{l}$ clients a service fee of $k_{t}$ and pay policymakers for access by supplying a portfolio consisting of financial contributions and policy proposals of a specific informational quality. They are able to choose informational quality because they possess a costly verification technology that allows them to investigate the potential spillovers from policy proposals.

We assume that each proposal a lobbyist receives incurs them a processing cost according to the increasing convex cost function $G\left(n_{t}^{l}\right)$. The $m_{t}^{l} \leq n_{t}^{l}$ proposals that are also investigated using the verification technology incur a further cost according to the increasing convex function $H\left(m_{t}^{l}\right){ }^{26}$

The payoff for lobbyist $l$ in $t$ is

$$
\Pi_{t}^{l}=k_{t} n_{t}^{l}-G\left(n_{t}^{l}\right)-H\left(m_{t}^{l}\right)-f_{t}^{l}+\frac{S_{t}}{T}
$$

where $f_{t}^{l}$ is the lobbyist's financial contribution to a policymaker, and $\frac{S_{t}}{T}$ is their share of aggregate spillovers. Notice that not all proposals have to be verified, nor presented. So the lobbyist's proposal adding-up constraint consists of $n_{t}^{l}=m_{t}^{l}+u_{t}^{l}+d_{t}^{l}$, where $u_{t}^{l}$ is the number of unverified but presented proposals and $d_{t}^{l}$ the number of proposals that are neither verified nor presented.

\footnotetext{
${ }^{25}$ We do not model the costs of establishing a lobbying firm or acquiring expertise, although this could easily be incorporate as a fixed cost. The essential elements needed to be a lobbyist are a good reputation and access to policymakers, expertise is secondary (Bertrand, Bombardini and Trebbi 2014).

${ }^{26}$ It is also assumed that $H^{\prime}(0)=G^{\prime}(0)=0$ and $H^{\prime \prime \prime}() \geq$.0 .
} 
As stated above a lobbyist receives access from policymakers in return for supplying a portfolio of proposals of a given informational quality and financial contributions. Hence, it is necessary to specify details of the lobbyist's verification technology. This technology returns a private signal $x \in\left\{x^{+}, x^{-}\right\}$correlated with the sign of the spillover from a proposal. If the signal is positive, $x^{+}$, then the probability of a positive spillover is higher than without investigation, $\rho\left(s^{+} \mid x^{+}\right)>\rho\left(s^{+}\right)$. Similarly, $\rho\left(s^{-} \mid x^{-}\right)>\rho\left(s^{-}\right)$.

It follows that investigated proposals with a positive signal have a greater expected social value than unverified proposals, and we assume that verified proposals which receive a negative signal have a negative expected social value. This is summarized as follows:

$$
\begin{gathered}
\rho\left(s^{+} \mid x^{+}\right)\left(\pi^{c}+s_{t}^{c}\right)+\rho\left(s^{-} \mid x^{+}\right)\left(\pi^{c}-s_{t}^{c}\right)>\rho\left(s^{+}\right)\left(\pi^{c}+s_{t}^{c}\right)+\rho\left(s^{-}\right)\left(\pi^{c}-s_{t}^{c}\right) \\
>0>\rho\left(s^{+} \mid x^{-}\right)\left(\pi^{c}+s_{t}^{c}\right)+\rho\left(s^{-} \mid x^{-}\right)\left(\pi^{c}-s_{t}^{c}\right) .
\end{gathered}
$$

The lobbyist's verification signals as well as the number of verified proposals and the amount of financial contributions are private information in $t .{ }^{27}$

\subsection{Policymakers}

Policymakers accept policy proposals from citizens or lobbyists and enact them such that the private benefits and social spillovers are realized. They do not possess an independent verification technology so act simply as gate-keepers. ${ }^{28}$ Unlike citizens and lobbyists the self-interested policymakers do not take the sum of spillovers as given. This motivates them to design implicit repeated agency contracts in the form of access rules.

In each period, a policymaker enjoys a share of spillovers from all enacted policy proposals and may receive financial contributions of $f_{t}^{c p}$ or $f_{t}^{l p}$, from each of their $c_{t}^{p}$ citizen-donor and $l_{t}^{p}$ lobbying contacts respectively. These financial contributions are discounted by $\alpha \in[0,1] .{ }^{29,30}$ This can be given a number of interpretations including the policymaker's degree of dishonesty or the effectiveness of in-kind transfers. In collecting contributions the policymaker incurs monitoring and accounting costs

\footnotetext{
${ }^{27} f_{t}^{l}$ may be thought of as a promise that remains to be honored.

${ }^{28}$ The notion of a policymaker as a gate-keeper is similar to Grossman and Helpman (1994). In our analysis a policymaker is not necessarily uninformed as they have a prior belief about the likelihood that a proposal has a positive spillover, what is important, is that a commercial lobbyist can improve available information.

${ }^{29} \mathrm{~A}$ financial contribution can be interpreted as any resource that yields a private benefit for a policymaker but does not generate policy relevant information or create social benefits - e.g., campaign contributions, network events, paid speeches, charity donations, future employment opportunities, etc.

${ }^{30} \mathrm{An}$ earlier version included an ego rent that motivated policymakers to accept political office. Here, for simplicity, we have normalized this to zero. This has no qualitative implications.
} 
according to the function $B\left(c_{t}^{p}+l_{t}^{p}\right)$, which is increasing and convex in the total number of agents from whom the policymaker receives contributions.

The payoff for policymaker $p$ in $t$ is then

$$
\Pi_{t}^{p}=\alpha \sum_{l=1}^{l_{t}^{p}} f_{t}^{l p}+\alpha \sum_{c=1}^{c_{t}^{p}} f_{t}^{c p}-B\left(l_{t}^{p}+c_{t}^{p}\right)+\frac{S_{t}}{T} .
$$

The policymaker's problem is to maximize the expected value of (2.7) subject to a time constraint that allows them each to enact a maximum of $A_{t}^{p}$ proposals per period. This is a somewhat complex problem. The expected quality of spillovers depends on the mix of proposals accepted from citizens and lobbyists and the verification choices of the latter; which are not observed by policymakers. Also, realized financial contributions depend on lobbyists honoring contribution promises. So to maximize their expected payoff a policymaker must select from whom to accept policy proposals and design an incentive scheme for lobbyists that solves both an information and a contracting problem.

\subsection{Political Access}

Given the institutional structure of lobbying, we follow Holmstrom (1981) in arguing that complex contracts are infeasible. ${ }^{31}$ Therefore, we adopt a simple approach similar to Esfahani and SalehiIsfahani (1989) and Black and Garen (1991) in the efficiency wage literature. ${ }^{32}$ Each policymaker designs implicit access rules for citizens and lobbyists, $\tilde{a}^{c p}($.$) and \tilde{a}^{l p}($.$) , that specify the conditions$ under which each receives a given amount of access. Because of the information structure, a failure to satisfy these conditions is not detected until the next period when punishment takes place in the form of denying them future access. ${ }^{33}$ This implies that commercial lobbyists cannot then attract their fee paying citizen-clients and that citizens with current access lose their future access. ${ }^{34}$ These are

\footnotetext{
${ }^{31}$ Holmstrom (1981) points out that simple fixed-wage contracts may not be generally optimal, but might perform better in circumstances when the optimal contract itself would be complex and too expensive to enforce. We believe that this is true for lobbying where there are no formal contract enforcement mechanisms, and publicity about "contractual disagreements" would probably not be desirable.

${ }^{32}$ The two key differences are that; lobbyists' efforts are indirectly compensated with political access that is valued in the market for lobbying services, and that lobbyists undertake efforts with different monitoring characteristics. Verification efforts are unobservable at $t$ and imperfectly observable at $t+1$, financial contributions are unobservable at $t$ and perfectly observable at $t+1$. Earlier efficiency wage models by Shapiro and Stiglitz (1984) and Sparks (1986) do not exhibit equilibrium dismissal of unlucky agents.

${ }^{33}$ The main qualitative predictions of our analysis remain the same if longer performance histories are considered. Sufficiently unlucky lobbyists will still be terminated at some point, and policymakers will have to share information rents so as to incent lobbyists. The main differences would be a quantitatively different turnover rates and information rents for lobbyists in equilibrium. Our current structure keeps the analysis more tractable and intuitive.

${ }^{34}$ Notice that this constitutes an equilibrium in a simple game between individual policymakers and lobbyists. If lobbyists believe they will be denied access in a period because they failed to meet the conditions specified in the previous period, they have no incentive to try to meet them in the current period. While policymakers correctly believing that lobbyists will not attempt to meet the conditions specified for the current period given that they failed
} 
precisely the sort of informal "insider rules" understood to mediate these forms of repeated political relationships.

\subsubsection{Access for Citizens}

A citizen with direct political access provides an unverified policy proposal and is expected to make a minimum financial contribution as specified by the access rule - i.e., $\tilde{a}^{c p}=\tilde{a}^{c p}\left(\bar{f}^{c}\right)$. If the citizen delivers this amount, then they are rewarded with access in the future. A failure to deliver will result in $\tilde{a}_{t+1}^{c p}=0$. We refer to citizens with direct access who receive policy favors as citizen-donors and denote to their contemporaneous and expected lifetime payoffs as $\Pi^{c d}$ and $V^{c d} .^{35}$

Given the incentives provided by the announced access rules, the citizen-donors' best-responses are straightforward. If they wish to continue their relationship with the policymaker they contribution exactly the required donation, $f_{t}^{c p}=\bar{f}^{c p}$, otherwise they pay nothing, $f_{t}^{c p}=0$. This can be summarized as the following:

$$
f_{t}^{c p}= \begin{cases}\bar{f}_{t}^{c p} & \text { if } V^{c d} \geq V^{c} \\ 0 & \text { otherwise }\end{cases}
$$

and where (2.8) can be interpreted as a version of the citizen-donor's participation constraint.

\subsubsection{Access for Lobbyists}

The political access rule announced by a policymaker to a lobbyist consists of a quadruple $\left\{\bar{q}_{t}^{l p}, \bar{f}_{t}^{l p}, \tilde{a}_{t}^{l p}, \tilde{a}_{t+1}^{l p}\right\}$, which specifies that if a lobbyist delivers $\tilde{a}_{t}^{l p}$ proposals today that realize the minimum informational quality level of $\bar{q}_{t}^{l p}$ combined in a portfolio with a minimum financial contribution of $\bar{f}_{t}^{l p}$, then they will be rewarded with access $\tilde{a}_{t+1}^{l p}>0$ in the following period. A failure to deliver either $\bar{q}_{t}^{l p}, \bar{f}_{t}^{l p}$, or $\tilde{a}_{t}^{l p}$ will result in $\tilde{a}_{t+1}^{l p}=0$.

We shall derive the political access rule from the policymaker's optimization problem. This requires that we construct the mapping between the policymakers' choice variables and their expected payoff function. We do this in stages. First, we explain the elements of an abstract political access rule, $\tilde{a}^{l p}($.$) , which, given that the spillovers are stochastic and efforts are unobservable, generates$ probabilistic outcomes for the lobbyists associated with any verification level choices. Second, given the probability distribution that describes the mapping from lobbyists' choices to outcomes we derive them in the previous period have no incentive other than to terminate the relationship.

${ }^{35}$ This formalizes the argument made in Krozner and Stratmann (1998) that the committee system of Congress facilitates the exchange of promised financial contributions for policy favors in an environment of repeated personal interactions. 
the lobbyists' best-responses to any given rule. Finally, we use the lobbyists' best-responses as a constraint on the problem that policymakers solve to find the optimal values for this access rule.

Clearly, the access rule must induce a lobbyist to undertake the actions desired by a policymaker. Why the access rule includes requirements for a number of proposals, and for specified financial contributions, is transparent. Ideally, the policymaker would also like to specify a required level of verification activity. However this is unobservable, so the access rule must condition on an observable measure correlated with verification activity. We assume that the policymaker conditions access on informational quality defined as the proportion of proposals that realize positive spillovers. ${ }^{36}$ In expected terms information quality can be expressed as

$$
E_{t}\left[q_{t}^{l p}\right]=\frac{\rho\left(x^{+}\right) \rho\left(s^{+} \mid x^{+}\right) m_{t}^{l p}+\rho\left(s^{+}\right) u_{t}^{l p}}{\tilde{a}_{t}^{l p}} .
$$

Employing $\tilde{a}_{t}^{l p}=\rho\left(x^{+}\right) m_{t}^{l p}+u_{t}^{l p}$, we obtain the number of verified proposals that are required to realize the specified expected information quality, which is

$$
m_{t}^{l p}=\frac{E_{t}\left[q_{t}^{l p}\right]-\rho\left(s^{+}\right)}{\rho\left(x^{+}\right)\left[\rho\left(s^{+} \mid x^{+}\right)-\rho\left(s^{+}\right)\right]} \tilde{a}_{t}^{l p} .
$$

However, the policymaker's problem in implementing an access rule requires they make inferences about $m_{t}^{l p}$ given observed quality. Taking expectations of (2.10) appropriately, they form a conditional expectation of the verification effort the lobbyist expended in $t$, that is

$$
E_{t+1}\left[m_{t}^{l p}\right]=\frac{q_{t}^{l p}-\rho\left(s^{+}\right)}{\rho\left(x^{+}\right)\left[\rho\left(s^{+} \mid x^{+}\right)-\rho\left(s^{+}\right)\right]} \tilde{a}_{t}^{l p},
$$

where $\tilde{a}_{t}^{l p}$ and $q_{t}^{l p}$ and are known to the policymaker in $t+1$.

Each policymaker can announce a quality threshold for policy proposals, $\bar{q}_{t}^{l p}$. If a policymaker observes $q_{t}^{l p} \geq \bar{q}_{t}^{l p}$ in $t+1$, then the relationship continues and the lobbyist receives political access in $t+1$; otherwise it is terminated. The lobbyist chooses $m_{t}^{l p}$ and not $q_{t}^{l p}$, which is stochastic. Therefore for any given choice there is an associated probability that $q_{t}^{l p} \geq \vec{q}_{t}^{l p}$. To compute this the lobbyists and policymakers need to construct a distribution over the likelihood that a mix of verified and unverified policy proposals will yield the desired informational quality. Formally, this distribution is hypergeometric; which leads to tractability problems. Fortunately, the hypergeometric distribution can be approximated by the continuous normal distribution, which is the approach that we adopt in

\footnotetext{
${ }^{36}$ We do not provide an algebraic representation of this to save on notation.
} 
what follows. ${ }^{37}$

Using (2.9), the observed quality of enacted policy proposals can be approximated by

$$
q_{t}^{l p}=\frac{\phi m_{t}^{l p}}{\tilde{a}_{t}^{l p}}+\epsilon_{t}^{l p},
$$

where $\phi=\rho\left(x^{+}\right)\left[\rho\left(s^{+} \mid x^{+}\right)-\rho\left(s^{+}\right)\right]$: The $\epsilon_{t}^{l p}$ s are identically independently normally distributed random variables with mean $\rho\left(s^{+}\right)$and variance $\sigma^{2}$. We write the marginal density as $w(\epsilon)$. Now we can state the probability distribution that maps verification efforts and the minimum informational quality into the likelihood of a terminated relationship. The likelihood a lobbyist is terminated because they supplied information of insufficient quality can be written

$$
\operatorname{Pr}\left(q_{t}^{l p} \leq \bar{q}_{t}^{l p}\right) \equiv D=\int_{-\infty}^{\epsilon^{*}} w(\epsilon) d \epsilon
$$

where $\epsilon^{*}=\bar{q}_{t}^{l p}-\frac{\phi m_{t}^{l p}}{\tilde{a}_{t}^{l p}}$ with $D_{\bar{q}}=w\left(\epsilon^{*}\right)>0, D_{m}=-\phi / \tilde{a}_{t}^{l p} w\left(\epsilon^{*}\right)<0$, and $D_{\tilde{a}}=\phi m_{t}^{l p} \tilde{a}^{-2} w\left(\epsilon^{*}\right)>0$. Therefore a lobbyist has an incentive to expend verification effort to reduce the likelihood of termination. ${ }^{38}$ Note that a greater minimum informational quality increases the likelihood of termination. Recall that given a policymaker perfectly observes the financial contribution in $t+1$, and that the access rule specifies the lobbyist will be terminated with probability one if they deliver less than the specified contribution.

At this point we are ready to derive the lobbyist's best-responses of $m_{t}^{*}=M\left(\bar{q}_{t}^{l p}, \bar{f}_{t}^{l p}, \tilde{a}_{t}^{l p}, \tilde{a}_{t+1}^{l p}\right)$ and $f_{t}^{*}=F\left(\bar{q}_{t}^{l p}, \bar{f}_{t}^{l p}, \tilde{a}_{t}^{l p}, \tilde{a}_{t+1}^{l p}\right)$ to the access rule $\left\{\bar{q}_{t}^{l p}, \bar{f}_{t}^{l p}, \tilde{a}_{t}^{l p}, \tilde{a}_{t+1}^{l p}\right\}$. Given these best-responses the policymaker will choose the optimal values for the desired informational quality and financial contributions.

\footnotetext{
${ }^{37}$ In Esfahani and Salehi-Isfahani (1989), the principal observes a signal that is equal to the agent's effort plus an unobservable error term, which is characterized with a continuous bell-shaped density function. Since a bell-shaped density function does not guarantee a unique solution to the agent's optimization problem and a continuous bestresponse function in a principal-agent framework, they make additional assumptions about the agent's cost of efforts to ensure a solution. In Black and Garen (1991) the principal observes a similar performance signal with a normally distributed error term. Our current problem has a different information structure. Each policy proposal has either a positive or negative spillover. Further, the lobbyist's verification technology returns either a positive or a negative signal. Given the binary outcomes and exogenous probabilities, the probability of achieving a specific quality threshold follows a hypergeometric probability distribution. The hypergeometric probability distribution is discrete but can be, for specific parameter values, approximated to either a Poisson or a normal probability distribution - see Fahrmeir et al. (1997). Following Jewitt (1988), the Poisson probability distribution fulfills the desired characteristics for the first-order approach of solving principal-agent problems. Unfortunately, the approximation of the hypergeometric probability distribution to a Poisson probability distribution requires that the number of presented proposals with a positive verification signal is relatively small in comparison to the lobbyist's portfolio. So the statistically appropriate approximation would be the normal distribution.

${ }^{38} \mathrm{It}$ is possible for the policymaker to increase the number of observations by incorporating a lobbyist's performance history. The analysis abstracts from the optimal political access rules and focuses on how repeated personal interactions can solve a policymaker's information and contracting problem.
} 


\subsection{The Lobbyist's Problem}

Each lobbyist takes the lobbying service fee, $k_{t}$, the citizen's current payoff, $\Pi_{t}^{c}$, and the political access rules of policymakers, $\tilde{a}^{l p}($.$) , with \tilde{a}_{t}^{l p}, \bar{q}_{t}^{l p}, \bar{f}_{t}^{l p}$, and $\tilde{a}_{t+1}^{l p}$ as given. In each period they choose their number of clients, $n_{t}^{l}$, the number of proposals to verify, $m_{t}^{l p}$, and the financial contribution to make, $f_{t}^{l p}$, taking into account the impact of these choices on the likelihood of maintaining their relationship with a policymaker. ${ }^{39}$ The lobbyist's optimal portfolio of policy proposals includes only proposals with positive verification signals and unverified proposals - i.e., $\tilde{a}_{t}^{l p}=\rho\left(x^{+}\right) m_{t}^{l p}+u_{t}^{l p} \cdot{ }^{40,41}$ Recall the expected lifetime payoff at the beginning of $t+1$ of a lobbyist and a citizen are $V^{l}$ and $V^{c}$. The lobbyist's optimization problem, writing $r \in[0,1]$ as the discount rate and treating $V^{l}$ and $V^{c}$ as parameters, can be expressed as

$$
\max _{n_{t}^{l}, m_{t}^{l p}, f_{t}^{l p}} \Pi^{l}=k_{t} n_{t}^{l}-G\left(n_{t}^{l}\right)-H\left(m_{t}^{l p}\right)-f_{t}^{l p}+\frac{D}{1+r} V^{c}+\frac{(1-D)}{1+r} V^{l}
$$

s.t. a current political access constraint of

$$
\tilde{a}_{t}^{l p}=\rho\left(x^{+}\right) m_{t}^{l p}+u_{t}^{l p} \text { for all } t
$$

with associated multiplier $\lambda_{t}^{l p}$, and the lobbyist's adding-up constraint

$$
n_{t}^{l}=m_{t}^{l p}+u_{t}^{l p}+d_{t}^{l} \text { for all } t
$$

with associated multiplier $\mu_{t}^{l p} \cdot{ }^{42}$

We first derive the first-order conditions with respect to the lobbyists choices over their number

\footnotetext{
${ }^{39}$ The number of presented but unverified proposals, $u_{t}^{l p}$, follows from $(2.15)$ and $m_{t}^{l p}$; the number of disappearing policy proposals, $d_{t}^{l}$, follows from $(2.16),(2.15)$, and $m_{t}^{l p}$.

${ }^{40}$ There is a very small probability that a lobbyist will have insufficient verified proposals with positive signals so as to simultaneously meet both the access and quality requirements. This can be modeled at significant cost in terms of algebraic complexity, but in terms of economics only adds a small deadweight loss arising from verification and processing costs incurred by the lobbying firms. We suppress this but can provide details on request.

${ }^{41} \mathrm{~A}$ proposal with a negative signal reduces the ex ante expected portfolio quality. Hence, a lobbyist would not report such a proposal and replace it with an unverified one. This implies that lobbyists would not find it optimal to lie to a policymaker, which is a crucial assumption for information externality models such as Bennedsen and Feldman (2006) and Dahm and Porteiro (2008).

${ }^{42}$ It is not optimal for a lobbyist with political access to become a citizen in $t$ if $k_{t} n_{t}^{l}-G\left(n_{t}^{l}\right) \geq \Pi_{t}^{c}$, otherwise no society member would want to be a lobbyist.
} 
of clients and level of verification. ${ }^{43}$ For the number of clients we obtain

$$
\frac{\partial \Pi^{l}}{\partial n_{t}^{l}}=k_{t}-G^{\prime}\left(n_{t}^{l}\right)+\mu_{t}^{l p} \leq 0
$$

and for verification effort

$$
\frac{\partial \Pi^{l}}{\partial m_{t}^{l p}}=-H^{\prime}\left(m_{t}^{l p}\right)-D_{m} \frac{\left(V^{l}-V^{c}\right)}{1+r}-\rho\left(x^{+}\right) \lambda_{t}^{l p}-\mu_{t}^{l p} \leq 0
$$

Equation (2.18) is essentially the lobbyist's incentive compatibility constraint. ${ }^{44}$ It provides their behavioral response in terms of their verification effort for a given probability of termination as specified by the policymaker's access rule. The immediate implication of (2.18) is:

Proposition 1. Lobbyists provide positive levels of unobservable verification effort in $t$ whenever policymakers can promise sufficient future benefits and lobbyists'verification efforts decrease the likelihood of being terminated by a policymaker. That is in $t, m_{t}^{l p}>0$, if $V^{l}>V^{c}$ and $D_{m}<0$.

Hence, as long as there are promised future benefits to being a lobbyist, $V^{l}-V^{c}>0$, and the lobbyist's verification effort decreases the likelihood of being terminated in the future, $D_{m}<0$, then they undertake a positive level of unobservable verification effort so as to maintain the relationship with the policymaker. ${ }^{45}$ Shortly, we shall show how this is crucial to the result that a policymaker may design a political access rule that allows them to escape a lobbying equilibrium without information transmisson.

At this point we are not quite ready to employ the participation and incentive compatibility constraints to solve the policymaker's optimization problem. It is well-known that the first-order approach to these sorts of agency problems may involve a nonconcave optimization problem. ${ }^{46}$ This would imply that the lobbyist's best-response, $m_{t}^{*}$, is not a continuous function. Hence, we require

\section{Assumption 1.}

$$
\frac{H^{\prime \prime}\left(m_{t}^{l p}\right)}{H^{\prime}\left(m_{t}^{l p}\right)}>\frac{D_{m m}}{D_{m}}=\frac{w^{\prime}\left(\epsilon^{*}\right) \phi}{w\left(\epsilon^{*}\right) \tilde{a}_{t}^{l p}}
$$

which ensures a continuous best-response function with unique optimal verification effort if $n_{t}^{l}>$

\footnotetext{
${ }^{43}$ The second-order conditions are $\frac{\partial^{2} \Pi^{l}}{\partial n_{t}^{l 2}}=-G^{\prime \prime}\left(n_{t}^{l}\right)<0$ and $\frac{\partial^{2} \Pi^{l}}{\partial m_{t}^{l p^{2}}}=-H^{\prime \prime}\left(m_{t}^{l p}\right)-D_{m m} \frac{\left(V^{l}-V^{c}\right)}{1+r} \gtreqless 0$.

${ }^{44}$ Note that $(2.17)$ and (2.18) depend on whether $n_{t}^{l} \geq m_{t}^{l p}$ and $\tilde{a}_{t}^{l p} \geq \rho\left(x^{+}\right) m_{t}^{l p}-$ i.e., $u_{t}^{l p} \geq 0$. If $u_{t}^{l p}>0$, then $\lambda_{t}^{l p}=0$ and $\mu_{t}^{l p}=0$. Otherwise there would be a corner solution with $\tilde{a}_{t}^{l p}=\rho\left(x^{+}\right) m_{t}^{l p}$ and $n_{t}^{l}=m_{t}^{l p}+d_{t}^{l}$ with $d_{t}^{l} \geq 0$.

${ }^{45}$ This follows at an interior solution from $H^{\prime}(0)=0$ and that $H($.$) is increasing and convex.$

${ }^{46}$ See Rogerson (1985) for a general discussion of the multiplicity problem in principal-agent frameworks.
} 
$m_{t}^{l p} \cdot{ }^{47}$ This assumption is maintained for the remaining analysis. ${ }^{48}$

Note however that this does not imply that the best-response is monotonic. At low and high levels of the information quality threshold the marginal value of verification to the lobbyist is low. This follows because for low levels of the threshold the lobbyist will almost certainly achieve the information quality requirement whereas at high levels they will almost certainly fail it. ${ }^{49}$ The bestresponse function for the lobbyist's verification effort can be now summarized by the following:

$$
m_{t}^{*}=M\left(\bar{q}_{t}^{l p}, \bar{f}_{t}^{l p}, \tilde{a}_{t}^{l p}, \tilde{a}_{t+1}^{l p}\right)
$$

With respect to financial contributions; a lobbyist has no incentive to make a contribution in excess of the minimum, $f_{t}^{l p}>\bar{f}^{l p}$. Furthermore, if any of their choices will lead to the relationship being terminated, then they will select $f_{t}^{l p}=0$ as their best-response. This can be summarized as the following:

$$
f_{t}^{l *}=F\left(\bar{q}_{t}^{l p}, \bar{f}_{t}^{l p}\right)=\left\{\begin{array}{ll}
\bar{f}_{t}^{l p} & \text { if } V^{l} \geq V^{c} \\
0 & \text { if } V^{l}<V^{c}
\end{array} \text { for a given }\left\{\bar{q}_{t}^{l p}, \bar{f}_{t}^{l p}, \tilde{a}_{t}^{l p}, \tilde{a}_{t+1}^{l p}\right\}\right.
$$

and where $(2.22)$ can be interpreted as a version of the lobbyist's participation constraint.

\subsection{The Policymaker's Problem}

Each policymaker takes the citizens' and lobbyists' best-responses to $\tilde{a}^{c p}($.$) and \tilde{a}^{l p}($.$) as well as the$ outcomes of the lobbying service market, $k_{t}$ and $n_{t}^{*}$, and the expected payoffs, $\Pi_{t}^{c}$ and $V^{c}$, as given. They also take the actions of other policymakers, $A_{t}^{-p}$, as given. Each policymaker then chooses the

\footnotetext{
${ }^{47}$ As noted earlier, the normal probability distribution does not fulfill Jewitt's (1988) general sufficiency conditions for the first-order approach. This would require we adopt a Poisson approximation. Unfortunately this makes the analysis intractable. So we employ a normal approximation and maintain assumption 1 so as to ensure that the second derivative, $\frac{\partial^{2} \Pi^{l}}{\partial m_{t}^{l p^{2}}}$, is negative. Notice that because $\frac{\partial^{2} \Pi^{l}}{\partial n_{t}^{l} \partial m_{t}^{l p}}=\frac{\partial^{2} \Pi^{l}}{\partial n_{t}^{l} \partial m_{t}^{l p}}=0$, this is sufficient for uniqueness. If $n_{t}^{l}=m_{t}^{l p}$, then the assumption would have to be $\frac{H^{\prime \prime}\left(m_{t}^{l p}\right)+G^{\prime \prime}\left(m_{t}^{l p}\right)}{H^{\prime}\left(m_{t}^{l p}\right)+G^{\prime}\left(m_{t}^{l p}\right)-k_{t}}>\frac{D_{m m}\left(\bar{q}, m_{t}\right)}{D_{m}\left(\overline{q_{t}}, m_{t}\right)}$.

${ }^{48}$ We will use from now on the statistical approximation such that $(2.18)$ is written as $-H^{\prime}\left(m_{t}^{l p}\right)+w\left(\epsilon^{*}\right) \frac{\phi}{\tilde{a}^{l p}} \frac{\left(V^{l}-V^{c}\right)}{1+r}-$ $\rho\left(x^{+}\right) \lambda_{t}^{l p}-\mu_{t}^{l p} \leq 0$.

${ }^{49}$ In a steady state the lobbyists best response in terms of verification effort to a change in the information requirement may be written

$$
\frac{\partial m^{*}}{\partial \bar{q}}=\frac{\overbrace{w^{\prime}\left(\epsilon^{*}\right) \frac{\phi}{\tilde{a}}\left(V^{l}-V^{c}\right)}^{(?)}+\overbrace{w\left(\epsilon^{*}\right) \partial V^{l} / \partial \bar{q}^{l p}}^{(-)}}{\underbrace{H^{\prime \prime}(.)+w^{\prime}\left(\epsilon^{*}\right) \frac{\phi^{2}}{\tilde{a}^{2}}\left(V^{l}-V^{c}\right)}_{(+)}} \gtreqless 0,
$$

since $w^{\prime}\left(\epsilon^{*}\right) \gtreqless 0$ as $\epsilon^{*} \lesseqgtr \rho\left(s^{+}\right)$we cannot ensure monotonicity. 
set, $\left\{c_{t}^{p}, \bar{f}_{t}^{c p}, l_{t}^{p}, \bar{q}_{t}^{l p}, \bar{f}_{t}^{l p}, \tilde{a}_{t}^{l p}, \tilde{a}_{t+1}^{l p}\right\}$, so as to maximize their payoff subject to the citizen-donors' and lobbyists' participation and incentive compatibility constraints as well as their own time constraint. The policymaker's optimization problem can be then written as

$$
\begin{aligned}
\max _{c_{t}^{p}, \bar{f}_{t}^{c p}, l_{t}^{p}, \bar{q}_{t}^{l p}, \bar{f}_{t}^{l p}, \tilde{a}_{t}^{l p}, \tilde{a}_{t+1}^{l p}}= & \alpha \sum_{c=1}^{c_{t}^{p}} f_{t}^{c p}+\alpha \sum_{l=1}^{l_{t}^{p}} f_{t}^{l p}-B\left(c_{t}^{p}+l_{t}^{p}\right)+\frac{s}{T} \rho\left(x^{+}\right) \sum_{l=1}^{l_{t}^{p}} m_{t}^{l p}\left[\rho\left(s^{+} \mid x^{+}\right)-\rho\left(s^{-} \mid x^{+}\right)\right] \\
& +\frac{s}{T}\left(c_{t}^{p}+\sum_{l=1}^{l_{t}^{p}} u_{t}^{l p}\right)\left[\rho\left(s^{+}\right)-\rho\left(s^{-}\right)\right]+\frac{1}{T} E\left[\sum_{c \in A^{-p}} s^{c}\right]
\end{aligned}
$$

subject to the policymaker's time constraint, $A^{p} \geq c_{t}^{p}+\sum_{l=1}^{l_{t}^{p}} \tilde{a}_{t}^{l p}$, the lobbyists' presentation constraint, $\tilde{a}_{t}^{l p} \geq \rho\left(x^{+}\right) m_{t}^{l p}+u_{t}^{l p}$, each citizen-donor's participation constraint, $\Pi^{c d} \geq \Pi^{c}$, each lobbying contact's participation constraint, $\Pi^{l} \geq \Pi^{c d} \geq \Pi^{c}$, and citizen-donors' and lobbyists' incentive compatibility constraints. In other words, each policymaker chooses how to optimally receive private benefits from financial contributions that are either provided by citizen-donors or commercial lobbyists and a share of social spillovers whose quality depends on verified and unverified proposals. Where each of these choices are constrained by the citizen-donors' and lobbyists' best-responses to the policymaker's access rules.

The following observations allow us to simplify the policymaker's optimization problem: Firstly, each positively verified or unverified proposal yields in expected terms a positive spillover share so a policymaker will choose to exhaust all their time resources. Secondly, each citizen-donor's participation constraint is binding, which implies that a policymaker extracts all available private rents from a citizen-donor in exchange for access.

Lemma 1. Each policymaker sets the citizen-donor's minimum contribution, $\bar{f}_{t}^{c p}$, equal to the citizendonor's discounted private rent. Mathematically, we have

$$
\bar{f}_{t}^{c p}=\frac{V^{c d}-V^{c}}{1+r}
$$

This result is straightforward. The citizen-donors' contributions are promised in period $t$ but observable in the next period; the policymaker then sets these contributions such that donors are indifferent between attempting to gain access directly as citizen-donors or indirectly by employing a commercial lobbyist. Further, we see immediately that the policymaker's time constraint determines $l_{t}^{p}$, leaving $c_{t}^{p}, \bar{q}_{t}^{l p}, \bar{f}_{t}^{l p}, \tilde{a}_{t+1}^{l p}$ as the remaining choice variables.

In a steady state, each policymaker then selects a quadruple, $\left\{c^{p}, \tilde{a}^{l p}, \bar{q}^{l p}, \bar{f}^{l p}\right\}$, so as to maximize 
their expected lifetime payoff subject to the citizen-donors' and lobbyists' participation and incentive compatibility constraints as well as their own time constraint. The policymaker's steady-state optimization problem can be written as maximizing their per-period payoff

$$
\begin{aligned}
\max _{c^{p}, \tilde{a}^{l p}, \bar{q}^{l p}, \bar{f}^{l p}} \Pi^{p}= & \alpha \sum_{c=1}^{c^{p}} f^{c p}+\alpha \sum_{l=1}^{l^{p}} f^{l p}-B\left(c^{p}+l^{p}\right)+\frac{s}{T}\left(c^{p}+\sum_{l=1}^{l^{p}} \tilde{a}^{l p}\right)\left[\rho\left(s^{+}\right)-\rho\left(s^{-}\right)\right] \\
& +\frac{s}{T} \rho\left(x^{+}\right) \sum_{l=1}^{l^{p}} m^{l p}\left[\rho\left(s^{+} \mid x^{+}\right)-\rho\left(s^{-} \mid x^{+}\right)-\rho\left(s^{+}\right)+\rho\left(s^{-}\right)\right] \\
& +\frac{1}{T} E\left[\sum_{c \in A^{-p}} s^{c}\right]
\end{aligned}
$$

subject to the policymaker's time constraint $A^{p} \geq c^{p}+\sum_{l=1}^{l^{p}} \tilde{a}^{l p}$ with Lagrange parameter $\gamma^{p}$ and the lobbyist's participation constraint, $V^{l} \geq V^{c}$, which may be written ${ }^{50}$

$$
(1+r)\left[k n^{l}-G\left(n^{l}\right)-H\left(m^{l p}\right)-f^{l p}\right] \geq r V^{c} \text { for all } l^{p} .
$$

Employing the citizen-donors' donation best-response, (2.8), and the lobbyists' verification and donation best-responses, (2.21) and (2.22), we may write the first-order conditions as:

$$
\begin{gathered}
\frac{\partial \Pi^{p}}{\partial c^{p}}=\alpha \frac{\partial f^{c *}}{\partial c^{p}}+\frac{s}{T}\left[\rho\left(s^{+}\right)-\rho\left(s^{-}\right)\right]-B^{\prime}\left(c^{p}+l^{p}\right)-\gamma^{p} \leq 0 \\
\frac{\partial \Pi^{p}}{\partial \tilde{a}^{l p}}=\alpha \frac{\partial f^{l *}}{\partial \tilde{a}^{l p}}+\frac{s}{T}\left[\rho\left(s^{+}\right)-\rho\left(s^{-}\right)\right]+\frac{s}{T} \psi \frac{\partial m^{*}}{\partial \tilde{a}^{l p}}-\gamma^{p} \leq 0 \\
\frac{\partial \Pi^{p}}{\partial \bar{q}^{l p}}=\alpha \frac{\partial f^{l *}}{\partial \bar{q}^{l p}}+\frac{s}{T} \psi \frac{\partial m^{*}}{\partial \bar{q}^{l p}} \leq 0
\end{gathered}
$$

and

$$
\frac{\partial \Pi^{p}}{\partial \bar{f}^{l p}}=\alpha \frac{\partial f^{l *}}{\partial \bar{f}^{l p}}+\frac{s}{T} \psi \frac{\partial m^{*}}{\partial \bar{f}^{l p}} \leq 0
$$

where $\psi=\rho\left(x^{+}\right)\left[\rho\left(s^{+} \mid x^{+}\right)-\rho\left(s^{-} \mid x^{+}\right)-\rho\left(s^{+}\right)+\rho\left(s^{-}\right)\right]$. Expressions (2.27) and (2.28) determine jointly the allocation of political access across citizen-donors and lobbyists. Note that $\frac{\partial f^{c *}}{\partial c^{p}}$ and $\frac{\partial f^{l *}}{\partial l^{p}}$ are at the extensive margin and are either zero or the required amount, $\bar{f}^{c p}$ or $\bar{f}^{l p}$. We discuss all

\footnotetext{
${ }^{50}$ The lobbyist's stationary participation constraint, $V^{l} \geq V^{c}$, follows from $(2.14)$ with $\Pi^{l}=V^{l}$ as well as the expected lifetime payoff for a citizen such that:

$$
\begin{gathered}
\Pi^{l}=k n^{l}-G\left(n^{l}\right)-H\left(m^{l p}\right)-f^{l p}+\frac{D}{1+r} V^{c}+\frac{(1-D)}{1+r} V^{l} \geq V^{c} \\
V^{l}=\frac{(1+r)\left(k n^{l}-G\left(n^{l}\right)-H\left(m^{l p}\right)-f^{l p}\right)}{r+D}+\frac{D}{r+D} V^{c} \geq V^{c},
\end{gathered}
$$
}

which reduces to (2.26). 
three possibilities for the allocation of access below.

Expressions (2.29) and (2.30) determine jointly the required mixture of commercial lobbying verification effort and contributions. In each of these cases the policymaker chooses a point on the lobbyist's incentive compatibility constraint (2.18), which represents a trade-off between information quality and financial contributions.

The first-order conditions together with (2.8), (2.18), and (2.22) describe all the possible solutions to the policymaker's optimization problem. There is an interior solution and six corner solutions for the optimal values of $c^{p}, f^{c p}, l^{p}, \tilde{a}^{l p}, m^{l p}, u^{l p}$, and $f^{l p}$. This may appear complex but each of the cases is entirely intuitive; some are novel and some have the appealing feature of corresponding to cases discussed in the previous literature. Since the corner solution in $u^{l p}$ adds little extra to our analysis, we focus on financial contributions and verification effort and present the interior solution and the corner solutions for these variables.

We begin with the first-order conditions that determine the allocation of political access across citizen-donors and commercial lobbyists and continue with the other two first-order conditions that determine the policymaker's optimal thresholds for the lobbyists' political access rules.

\subsubsection{Allocation of Access}

Focusing on (2.27) and (2.28), the allocation of political access can be described by the following.

Proposition 2. The allocation of political access may take one of the following forms:

(i) Only access for citizen-donors, $c^{p}=A^{p}$ and $\sum_{l=1}^{l^{p}} \tilde{a}^{l p}=0$, if

$$
\alpha \frac{\partial f^{c *}}{\partial c^{p}}-B^{\prime}\left(A^{p}\right)>\alpha \frac{\partial f^{l *}}{\partial \tilde{a}^{l p}}+\left.\frac{s}{T} \psi \frac{\partial m^{*}}{\partial \tilde{a}^{l p}}\right|_{\tilde{a}^{l p}=0} \forall c^{p} \text { and } l^{p} .
$$

(ii) Only access for commercial lobbyists, $c^{p}=0$ and $\sum_{l=1}^{l^{p}} \tilde{a}^{l p}=A^{p}$, if

$$
\alpha \frac{\partial f^{l *}}{\partial \tilde{a}^{l p}}+\left.\frac{s}{T} \psi \frac{\partial m^{*}}{\partial \tilde{a}^{l p}}\right|_{\sum_{l=1}^{l p} \tilde{a}^{l p}=A^{p}}>\alpha \frac{\partial f^{c *}}{\partial c^{p}}-B^{\prime}\left(l^{p}\right) \forall c^{p} \text { and } l^{p} .
$$

(iii) Access for citizen-donors and commercial lobbyists, $c^{p}>0$ and $\sum_{l=1}^{l^{p}} \tilde{a}^{l p}>0$ with $c^{p}>0+$ $\sum_{l=1}^{l^{p}} \tilde{a}^{l p}=A^{p}$, if

$$
\alpha \frac{\partial f^{c *}}{\partial c^{p}}-B^{\prime}\left(c^{p}+l^{p}\right)=\alpha \frac{\partial f^{l *}}{\partial \tilde{a}^{l p}}+\left.\frac{s}{T} \psi \frac{\partial m^{*}}{\partial \tilde{a}^{l p}}\right|_{0<\tilde{a}^{l p}<A^{p}} .
$$


The allocation of political access follows from the citizen-donors' and lobbyists' relative abilities to deliver resources. Citizen-donors internalize the private benefits of their policy proposals and do not face additional overhead costs in delivering financial contributions. On the other hand, commercial lobbyists can deliver credible information, and bundle contributions of multiple clients so as to save policymakers the monitoring and accounting costs associated with financial contributions. For the first case the citizen-donors' comparative advantage in offering contributions dominates the comparative informational and scale advantages of commercial lobbyists. ${ }^{51}$ This is more likely if the policymaker's spillover shares and potential information gains from lobbyists are small, the policymaker's desire for contributions is high, and the policymakers' monitoring and accounting costs are not too high.

In the second case, where commercial lobbyists crowd out citizens from political access, policymakers either request verification effort, financial contributions, or a combination of both. Political capture by commercial lobbyists arrises because of commercial lobbyists' advantages in providing credible information, bundling financial contributions, or both. ${ }^{52}$

For the interior case, a policymaker allocates political access to both citizen-donors and commercial lobbyists and balances the comparative advantages of both. Citizen-donors have their proposals enacted in exchange for larger (relative to lobbyists) per-proposal financial contributions, while commercial lobbyists provide either credible information, contributions, or a mix of both. We focus on the interior solution as it is probably the most interesting case, and also the most empirically relevant as demonstrated by Figure 1. The other corner solutions will be discussed briefly later.

\subsubsection{Commercial Lobbying}

The first-order conditions (2.29) and (2.30) to the policymaker's optimization problem (2.25) give the access rules they announce to commercial lobbyists, these specify the desired information quality and minimum financial contributions that the policymaker requires in exchange for access $\tilde{a}^{l p}$. There are three possible maxima if a policymaker decides to allocate access to commercial lobbyists: an interior solution at which commercial lobbyists provide both informational lobbying effort and financial contributions, a corner solution at which commercial lobbyists specialize in information provision, and another corner solution at which commercial lobbyists are reduced to money-delivery agents.

\footnotetext{
${ }^{51}$ This case actually illustrates Krozner and Stratmann's (1998) argument of repeated interactions between special interests and Congress for quid pro quo donations for policies in the absence of binding contracts.

${ }^{52}$ This case is similar to Groll and Ellis $(2013,2014)$ where by assumption all political access would be allocated to commercial lobbyists. There only commercial lobbyists engage in observable lobbying efforts and guaranteed donations.
} 
The implicit interior solutions for the optimal quality threshold, $\bar{q}^{*}$, and the minimum financial contribution, $\bar{f}^{*}$, are then defined by the lobbyists's best-responses described by (2.21) and (2.22) and the policymaker's first-order conditions (2.29) and (2.30) equated to zero. Following Proposition (1) we have $V^{l}>V^{c}$ for the interior solution. ${ }^{53}$ The convexity of $F($.$) ensures that this solution is$ unique. Given the solutions for the policymaker's optimal access rule, the induced verification effort, $m^{*}$ and submitted payment, $f^{*}$, follow immediately from the lobbyists best responses.

Note that the relationship between $\bar{q}^{l p}$ and $m^{*}$ is not monotonic, because the lobbyist's bestresponse is not monotonic. At both high and low levels of $\bar{q}^{l p}$ the lobbyist has little incentive to engage in verification. Given $n$ and $k$, the optimal minimum financial contribution of $\bar{f}^{l p}$ follows from the lobbyist's incentive compatibility constraint, described in (2.18), and the pair $\left\{\bar{q}^{l p}, m^{*}\right\}$. However, the relationship between $\bar{q}^{l p}$ and $\bar{f}^{l p}$ is monotonic and decreasing. We derive the amount of political access and the number of lobbying contacts when we solve for the equilibrium.

In the interior solution, the policymakers demand of every lobbyist information improvement and positive financial contributions - i.e., $\bar{q}^{l p}>0$ as well as $\bar{f}^{l p}>0$.

Lemma 2. It follows from (2.29) and (2.30) equated to zero and $M_{\bar{f}} l_{p}()<$.0 and $F_{\bar{f}^{l p}}()=$.1 that

$$
H^{\prime}\left(m^{l p}\right) \underbrace{+H^{\prime \prime}\left(m^{l p}\right) \frac{r+D}{w\left(\epsilon^{*}\right)}}_{(a)}=\frac{1}{\alpha} \underbrace{\left(\frac{s \psi}{T}\right)}_{(b)} \underbrace{\left(\frac{\phi}{\tilde{a}^{l p}}\right)}_{(c)} .
$$

Lemma 2 essentially describes a policymaker's trade-off between a greater quality threshold, to incent lobbyists' verification efforts, and larger minimum financial contribution. The immediate implication of this trade-off is

Proposition 3. The desired unobservable verification effort depends on the trade-off faced by the policymaker between expected improved spillover shares and financial contributions and their relative weights in the objective function. Further, the desired level of verification effort per firm is less than would be found under full information.

Proposition 3 may be understood by considering the policymaker's incentives. The right-hand side of (2.34) is the marginal benefit to a policymaker of inducing an increase in the lobbyists verification effort by margainally adjusting the required quality threshold. This is the expected increment to their share of spillovers, term (b), weighted by their relative importance in the policymaker's objective

\footnotetext{
${ }^{53} \mathrm{As}$ is standard in principal-agent frameworks with asymmetric information the agent must enjoy information rents; this relaxes the participation constraint.
} 
function, $\frac{1}{\alpha}$. The left-hand side is the marginal cost, and involves both the direct and indirect costs of verification. The direct cost arrises because the lobbyist is induced to engage in more costly verification and hence can only afford a smaller financial contribution to the policymaker. The indirect cost involves the need for the policymaker to provide sufficient incentive for the lobbyist to honor the promised portfolio of information improvement and financial contributions. An increment to $m^{l p}$ reduces the incentive for the lobbyist to honor this promise and so they must be offered extra marginal compensation represented by the information rent terms (a) and (c).

Expression (2.34) is the same as the solution equation for the level of verification that arises in the full-information problem except for the additional terms (a) and (c), which represent the distortion introduced by the need for the policymaker to incent the lobbyist by allowing them information rents. ${ }^{54}$ The distortion is larger; (i) the less precisely the policymaker can infer the lobbyist's effort from observations on the realized information quality - i.e., the smaller are $w\left(\epsilon^{*}\right)$ and $\phi / \tilde{a}^{l p}$; (ii) the more convex are the lobbyist's costs - i.e., the greater is $H^{\prime \prime}($.$) ; and (iii) the less the lobbyist values$ an ongoing relationship - i.e., the greater is $r+D$.

Our assumptions ensure the existence of an interior solution for some parameter values, where the financial contribution component of the access rule follows jointly from (2.18) and (2.34). Surprisingly, the characteristics of this interior solution are novel. We show that contrary to the results found in the existing literature individual lobbyists do not specialize in either transmitting information or making financial contributions but rather provide an optimal mix of both. ${ }^{55}$ This corresponds to what is observed in the lobbying industry. ${ }^{56}$

Furthermore, there has been considerable comment both in the popular press and in the empirical literature on the importance of repeated relationships between policymakers and lobbyists. Here, our Propositions 1 to 3 jointly explain why these repeated relationships between commercial lobbyists and policymakers arise as they allow policymakers to design implicit access rules that solve a contracting problem over financial contributions and an information problem over the quality of policy proposals. Furthermore, when policymakers allocate some access to citizen-donor this is still done on the basis

\footnotetext{
${ }^{54}$ See Proposition 4 of Groll and Ellis (2014).

${ }^{55}$ For example, Bennedsen and Feldmann (2006) investigate information externalities when multiple interest groups attempt to influence a single policy. The information externality reduces an interest group's incentive to provide information and results in the interest group's specialization in either means. Dahm and Porteiro (2008) show that the provision of information may harm a single interest group and that financial contributions can either complement or substitute for information transfers. Cotton (2009) analyzes a policymaker's trade-off between selling policy favors without information provision and selling access in exchange for contributions and observable information. The current analysis provides a prediction that is similar to Cotton (2009). As a policymaker receives a smaller share in social spillovers, $s / T$, policymakers are more likely to demand contributions, i.e. sell favors.

${ }^{56}$ This observation has been shared in interviews with the authors by professional lobbyists, and is also analyzed in Bertrand, Bombardini, and Trebbi (2014).
} 
of a repeated relationship as this allows a solution to the contracting problem.

\subsubsection{The Policymaker's Lobbying Trade-off}

Combining the last statement of Proposition 2 with Lemma 1, $F_{f^{c p}}($.$) , and the derivations of Lemma$ 2, we may describe the trade-off faced by a policymaker between allocating time to commercial lobbyists and citizen-donors who in our analysis can be interpreted as unitary special interest groups.

Proposition 4. The policymaker's trade-off between special interest group lobbying and commercial lobbying follows from:

$$
\alpha \bar{f}^{c}=\left(\frac{s \psi}{T}\right) \frac{\partial m^{*}}{\partial \tilde{a}^{l p}}+B^{\prime}\left(c^{p}+l^{p}\right) .
$$

Expression (2.35) describes a trade-off between the discounted contribution delivered by a citizendonor on the left-hand-side and, on the right-hand-side, the discounted information improvement benefits as well as contribution bundling scale effects provided by a lobbyist. Hence, the allocation of political access depends on the policymaker's basic trade-off between information and financial contributions together with the relative advantages of citizen-donors and commercial lobbyists in delivering these requirements. The citizen-donor's enjoy an advantage in making contributions that arises from a lack of overhead costs and the greater willingness to donate as they realize the full private benefits of enacted policies - see Lemma 1. The commercial lobbyists' enjoy an advantage in providing information both because they possess the information verification technology and may be incented to employ it as the policymakers require. Further, commercial lobbyists enjoy economies of scale in "bundling" financial contributions so as to lower per-proposal overhead costs. If these scale effects are sufficiently large, they may then also enjoy an advantage in delivering financial contributions..$^{57}$

\subsubsection{Corner Solutions}

The first-order conditions (2.27) and (2.28) admit two corner solutions where political access is exclusively granted to either citizen-donors or lobbyists. Further, the other first-order conditions (2.29) and (2.30) admit two corner solutions where policymakers demand only information improvement or only financial contributions from lobbyists. ${ }^{58}$ Overall, there are four corner solutions we discuss

\footnotetext{
${ }^{57}$ Most larger U.S. lobbying firms maintain their own Political Action Committee (PAC) - an example is Patton Boggs, which is one of the largest lobbying firms, which maintains a PAC to which even their partners donate annually.

${ }^{58}$ However, because of the absolute advantage of citizen-donors in providing financial contributions without operating a firm, policymakers always allocate at least some access to citizen-donors when they desire financial contributions. Hence, there are no corner solutions in which only commercial lobbyists receiver political access in exchange for either information and contributions or contributions only.
} 
these only briefly here, formal derivations may be found in the Supplemental Appendix.

Only Direct Lobbying Following the first part of Proposition 2 policymakers may allocate all access to citizen-donors and extract all available rents via financial contributions. This outcome arises when policymakers face a pure contracting problem and commercial lobbyists' economies of scale in bundling contributions do not outweigh their own costs of operation. The allocation of access follows a simple quid pro quo principle of contributions for access and policies, which is for $\alpha \neq 1$ socially wasteful.

Only Commercial Lobbying Policymakers may allocate all political access to lobbyists when the policymaker faces a pure information problem. There will be only be an information problem if $\alpha$ gets sufficiently small, spillover shares sufficiently large and important, or the lobbyist's verification technology is very effective. Conversely, there will be only a contracting problem or a mixture of both problems when the opposite conditions hold.

Lobbying Specialization Two other corner solutions arise when there is an interior solution for the allocation of access. Citizen-donors receive access in exchange for contributions and commercial lobbyists are expected to provide either all information or all contributions. ${ }^{59}$ Pure specialization of citizen-donors and lobbyists arises when the policymaker faces a contracting and information problem but the lobbyists' economies of scale in contributions are insufficient. Specialization by both in providing contributions arises if the policymaker faces a pure contracting problem and the policymaker's accounting costs are large.

Regulatory Implications A simple but important point here is that whether we get a corner solution depends upon the lobbyist's incentive compatibility constraint and their verification technology as well as the policymaker's preferences. There is a policy debate in which it is presumed that financial contributions are significant and distortionary. The corner solutions illustrate when the presumed financial contributions are not present and when they may be a major concern.

When it is deemed necessary to eliminate financial contributions, then our analysis points out that this can be achieved via policies that impact the policymaker's optimization problem at different points. For example, zero financial contributions may arise if a policymaker whose preferences involve

\footnotetext{
${ }^{59}$ The case where there are only financial contributions, either provided by citizen-donors or citizen-donors and lobbyists, seems to formalize Krozner and Stratmann's (1998) empirical argument that the committee system of U.S. Congress allows for repeated interactions that solve the contracting problem of legislative favors for campaign contributions.
} 
$\alpha \approx 0$ can be selected, this might be interpreted as choosing an honest policymaker. Alternatively, a restriction of payments to in-kind contributions or by making contributions illegal so that they must be hidden at some cost, may again yield $\alpha \approx 0$. Second, policymakers may be induced to choose zero financial contributions by policies that make them value spillover shares more. ${ }^{60}$

\section{Equilibrium}

We now turn our attention to embedding the political access rules in a general-equilibrium framework, and will work primarily with the empirically relevant interior solutions, where both citizen-donors and lobbyists receive political access and lobbyists provide both information and contributions. The interior solution with both commercial lobbyists and citizen-donors is consistent with Bertrand, Bombardini, and Trebbi (2014)'s empirical analysis of the U.S. lobbying industry. They show that both types exist and that commercial lobbyists working on many issues make greater campaign contributions than in-house lobbyists. ${ }^{61}$

The interior equilibrium is characterized by a steady state in the markets for political access, lobbying labor, and commercial lobbying services. The political access market is in equilibrium if given the policymakers' access rules and the number of lobbyists and citizen-donors, the policymakers' total time endowment is precisely exhausted. The labor market is in equilibrium if the inflow of citizens into the lobbying industry is equal to the outflow of lobbyists who have lost political access to policymakers and return to being citizens. Finally, the market for commercial lobbying services is in equilibrium if demand equals the supply for intermediation services. In the following, we characterize the symmetric steady state equilibrium by employing the interior solution to the policymaker's problem.

\subsection{The Market for Political Access}

As shown in the policymaker's problem, policymakers want to employ all political resources and allocates political access to both citizen-donors and lobbyists - i.e., $A_{t}=\bar{P} A^{p}$. The symmetric equilibrium requires that the allocation of access per lobbyist and citizen-donor, as defined by the optimal access rule, multiplied by the equilibrium number of lobbyists and citizen-donors just exhausts the

\footnotetext{
${ }^{60}$ This apparently trivial point is subtler than it first may appear. For example, residency requirements for policymakers may induce them to care more about spillover shares that arise in their own jurisdictions.

${ }^{61}$ The equilibrium outcomes for all corner solutions can be found in the supplemental appendix.
} 
sum of the policymakers' time endowment, viz

$$
C_{t}^{d}+\tilde{a}_{t}^{l p} L_{t}=\bar{P} A^{p}
$$

with $C_{t}^{d}=\sum_{p=1}^{\bar{P}} c_{t}^{p}$ and $L_{t}=\sum_{p=1}^{\bar{P}} l_{t}^{p}$.

Notice that (3.1) does not imply that the identity of the $L_{t}$ lobbyists is the same across periods. While all lobbyists are incented to both supply the requisite verification effort and financial contributions by the access rules, this does not mean that some of them will not be unlucky with respect to actual realized information quality. The unlucky lobbyists will be replaced by new lobbyists drawn from the pool of citizens to prevent future shirking. ${ }^{62}$ The likelihood that an lobbyist will be unlucky is denoted by $D_{t}$.

\subsection{The Lobbying Labor Market}

The flow of lobbyists who lose access in $t$ and therefore become citizens is $D_{t} L_{t}$. Therefore, for there to be an equilibrium this must equal the number of citizens flowing in the other direction. It follows that if we write the probability a given agent will enter the market for political access and become a lobbyist as $e_{t}$, then the equilibrium condition is

$$
e_{t}\left(C_{t}+D_{t} L_{t}\right)=D_{t} L_{t}
$$

Note however, that for (3.2) to hold it must be the case that citizens and "unlucky" lobbyists wish to enter the lobbying industry - i.e., $V^{l} \geq V^{c}$ in the steady state. We shall provide further details shortly. ${ }^{63}$

\subsection{The Market for Lobbying Services}

Only citizens who are not citizen-donors with direct political access $\left(C_{t}^{-d}\right)$ are potential lobbying clients. The equilibrium in the market for lobbying services requires that the citizens' willingness to pay equals to the lobbyists' willingness to accept, which determines $k_{t}$. Employing (2.4) and (2.17),

\footnotetext{
${ }^{62}$ Policymakers find this optimal despite being aware that the lobbyist was just unlucky because they must discourage future shirking.

${ }^{63}$ We assume that unlucky lobbyists are not stigmatized, given that in equilibrium it will be the case that all lobbyists that lose political access are indeed merely unlucky this seems to make sense.
} 
we obtain the equilibrium condition

$$
G^{\prime}\left(n_{t}^{l}\right)=k_{t}=\frac{\tilde{a}_{t}^{l p}}{n_{t}^{l}} \pi^{c} \text { for every } l \text { and } t
$$

\subsection{Payoffs}

The steady state equilibrium payoffs for commercial lobbyists are

$$
V^{l}=\left(\frac{1+r}{r}\right)\left(\frac{r+e}{1-e}\right) \frac{H^{\prime}\left(m^{l p}\right)}{h^{*}}>0
$$

for citizen-clients

$$
V^{c}=\frac{(1+r) e}{r+e} V^{l}>0
$$

and for citizen-donors

$$
V^{c d}=\pi^{c}+\frac{V^{c}}{1+r}=\pi^{c}+\frac{e}{r+e} V^{l}>0
$$

\subsection{Full Equilibrium}

The full symmetric steady state equilibrium is characterized by the previously described equilibrium conditions (3.1), (3.2), (3.3) as well as the population constraint, adding-up conditions, access rules, and a formal description of the asset value equations incorporating the citizen-donors' and lobbyists' choices. The features of the mathematical solution can be described by

Lemma 3. The symmetric steady state equilibrium involves i) political access for both citizen-donors and lobbyists, ii) financial contributions by citizen-donors and lobbyists and information efforts by lobbyists, iii) citizens without direct access are lobbying clients, iv) dismissal of "unlucky" lobbyists and entry into the commercial lobbying industry by citizen-clients, and v) positive rents for commercial lobbyists which spill over through entry-exit.

In the following we present the comparative statics effects of changes in some of the model's key parameters on the steady state equilibrium when there is an interior solution to the policymaker's information and contracting problems.

\subsection{Selected Comparative Statics}

The comparative static effects are divided into what are termed substitution and resource effects. The substitution effects arise from parameter changes that cause policymakers to face different trade-offs 
in choosing between contributions from citizen-donors and lobbyists and setting information quality thresholds for lobbyists. The resource effects arise from changes in citizens' willingness to pay for either direct or indirect lobbying, which are leading to changes in the overall level of resources in the lobbying industry. The comparative statics effects are reported in Table $2 .{ }^{64}$ We shall provide some intuition into these comparative statics results in this section. In a later section we shall discuss how they relate to the characteristics and recent changes in the lobbying industry.

\begin{tabular}{|c|c|c|c|c|c|c|c|c|c|c|c|c|}
\hline & $d m^{*}$ & $d \bar{q}^{*}$ & $d u^{*}$ & $d f^{l *}$ & $d f^{c *}$ & $d n^{*}$ & $d e^{*}$ & $d L^{*}$ & $d C^{d *}$ & $d V^{l *}$ & $d V^{c d *}$ & \\
\hline$d \alpha$ & $(-)$ & $(-)$ & $(+)$ & $(+)$ & $(+)$ & $(0)$ & $(0)$ & (0) & $(0)$ & $(-)$ & $(-)$ & \multirow{3}{*}{ Substitution Effects } \\
\hline$d s$ & $(+)$ & $(+)$ & $(-)$ & $(-)$ & $(-)$ & $(0)$ & $(0)$ & $(0)$ & $(0)$ & $(+)$ & $(+)$ & \\
\hline$d \psi$ & $(+)$ & $(+)$ & $(-)$ & $(-)$ & $(-)$ & $(0)$ & $(0)$ & $(0)$ & $(0)$ & $(+)$ & $(+)$ & \\
\hline$d A^{p}$ & $(0)$ & $(?)$ & $(0)$ & $(+)$ & $(+)$ & $(0)$ & $(-)$ & $(-)$ & $(+)$ & $(-)$ & $(-)$ & \multirow{2}{*}{ Resource Effects } \\
\hline$d \pi^{c}$ & $(0)$ & $(?)$ & $(0)$ & $(+)$ & $(+)$ & $(+)$ & $(-)$ & $(-)$ & $(+)$ & $(-)$ & $(+/-)^{a}$ & \\
\hline
\end{tabular}

a) $\operatorname{As} \frac{\tilde{a}^{l p 2} L n^{l}(1+r) D\left(C^{d}+C^{-d}+L\right) H^{\prime}(.)}{\left(C^{d}+C^{-d}+L D\right)^{2}} \lesseqgtr(e-1)^{2} r \phi\left(\tilde{a}^{l p}-n^{l}-1\right) D^{\prime}().\left(\tilde{a}^{l p} \pi^{c}+n^{l 2} G^{\prime \prime}().\right)$

Table 2: Selected Comparative Statics of the Market Equilibrium.

Consider first an increase in the weight placed by policymakers on financial contributions, $\alpha$, which changes the form in which policymakers prefer to extract rents from lobbyists. Policymakers reduce the quality threshold for presented proposals and induce lobbyists to present fewer verified proposals, $m^{*}$, and more unverified proposals, $u^{*}$. They also increase required financial contributions, $f^{l *}$ and $f^{c *}$. Given that policymakers put more weight on financial contributions and induce less verification effort, it follows that lobbyists earn lower information rents and their expected lifetime payoffs, $V^{l *}$, decline, furthermore this also implies lower payoffs for citizen-donors, $V^{c d *}$. Further, given that $n^{*}$ and $L^{*}$ are invariant with respect to $\alpha$, this immediately implies that the total number of presented proposals and the amount of private benefits are constant while the expected value of total spillovers must decline.

An increase in the magnitude of spillovers, $s$, or an improvement in the efficiency of the verification technology, $\psi$, work through the lobbying firm's participation constraints to affect the trade-off between information quality and financial contributions faced by policymakers. They both raise the

\footnotetext{
${ }^{64}$ Formal derivations run to several pages; supplemental Mathematica notebooks giving the details are available from the authors on request.
} 
expected returns to verification, and have the opposite effect of policymakers putting more weight on financial contributions. Policymakers increase their quality thresholds inducing more verified proposals and fewer unverified proposals to be presented, and decrease their required financial contributions. Overall these changes must increase expected information rents. These gains are then shared between the policymakers and lobbying firms with both enjoying higher expected lifetime payoffs. ${ }^{65}$ Another way to view these results is that a change in $s$ or $\psi$ influences the policymaker's preferred method of rent extraction in the political access market. Notice that these effects do not impact the equilibrium in the market for commercial lobbying services. The number of lobbyists remains the same as does the total number of their citizen-clients.

We now turn to the comparative static effects that arise from changes in resources. These include changes in the amount of resources per policymaker, $d A^{p}$, and the private benefit from an enacted proposal, $d \pi^{c}$. First consider the effect of an increase in time for each policymaker. The additional time does not affect the policymaker's trade-off between contributions and verifications demanded from lobbyists but provides opportunities to receive greater private rents from more citizen-donors. Since there are additional citizen-donors there are fewer commercial lobbyists, and there is a decrease in turnover amongst lobbyists. This reduces the expected lifetime payoffs for both lobbyists and citizen-donors. The unchanged number of verified proposals but fewer lobbyists implies a reduction in the expected quality of spillovers. Our results concerning the effects of changes in $d A^{p}$ are of particular interest. In the discussion section that follows we shall explain how recent changes in the nature of politics in the United States imply $d A^{p}<0$, and that this in turn may explain policymakers' increasing reliance on commercial lobbyists. Essentially, increased scarcity in policymakers' time allows them to consideration fewer policy proposals, implying that they rely more on the efficiency of commercial lobbyists, who actually turn into partners. As Levine (2008, p. 133) remarks, "lobbyists are now really adjuncts to the process."

Finally consider the effects of an increase in the private benefit from a presented proposal. All else equal this must raise both the citizen-donors' willingness to contribute and the demand price for lobbying services and hence the number of proposals accepted by lobbying firms. Given the population adding up constraint this implies there must be fewer but larger lobbying firms. However, the citizens' greater willingness to donate or pay for lobbying services implies that citizen-donors' individual contributions increase but do not affect the lobbyists' economies of scale in bundling individual contributions. Hence, citizen-donors receive more access and crowd out lobbyists. The policymakers'

\footnotetext{
${ }^{65}$ Indeed citizen-clients and citizen-donors benefit too in as much as they are potential future lobbyists.
} 
trade-off between verification effort and contributions is not directly affected and policymakers expect the same verification but extract greater remaining resources from larger lobbying firms. This decreases the lobbyists' information rents and hence the expected lifetime payoffs for lobbyists. However, the effect of an increase in private benefits on the lifetime payoffs of citizen-donors is ambiguous. Lower information rents and less entry tend to reduce their payoffs but the increase in the value of direct access tends to increase their payoffs. However, fewer lobbyists who verify the same number of proposals per lobbyist results in less overall verification and reduces the expected quality of enacted proposals.

We are now able to consider some normative implications of our equilibrium results.

\section{The Social Value of Cronyism}

The observed repeated relationships between policymakers and lobbyists are frequently referred to using the pejorative term cronyism, and are assumed to represent some kind of political capture by a lobbyist or special interest group. The implication being that this then leads to negative welfare and distributional consequences. ${ }^{66}$ The analysis developed above tells us that this popular and apparently economically intuitive conclusion may be far from correct. The populist view is that repeated relationships between policymakers and lobbyists crowd out others from the political process to the detrement of social welfare and with negative distributional consequences. However, this overlooks the fact that these relationships solve both an information and contracting problem. Furthermore, casual economic intuition suggests that the welfare outcomes with repeated relationships in a world of asymmetric information must be inferior to the outcomes in a world of full information, where the lobbying firm's efforts and signals are observable to the policymaker. But, this neglects the fact that the full information world may involve other distortions such that cronyism may involve a second-best welfare improvement.

Consider the distributional consequences of repeated agency under asymmetric information. It is shown above that policymakers must allow lobbyists information rents to incent them to engage in unobservable verification effort. Furthermore, because of turnover in the political access market and entry in the lobbying service market citizens enjoy a share of these expected rents. But recall that it is still necessary for policymakers to create entry barriers into the political access market. If they do

\footnotetext{
${ }^{66}$ For example, the conviction of lobbyist Jack Abramoff and multiple Congress members for tax evasion, fraud, and bribery confirmed the public's critical view of close lobbyist-policymaker relationships (Schmidt and Grimaldi 2006) and also resulted in regulatory reforms.
} 
not protect lobbyists from entry, they will not be able to credibly promise them the future rents which make it in their best interests to fulfill the terms of the implicit contracts. In other words, satisfy the incentive compatibility condition - i.e., from (3.5) and (3.6) it follows that $V^{l *}>V^{c d *}>V^{c *}>0$. This contrasts with a world of full information, where all private rents are captured by policymakers (Groll and Ellis 2014), and which is empirically consistent (Ansolabehere, de Figureido, Snyder 2003; de Figueiredo and Richter 2014). ${ }^{67}$ In summary we stress

Proposition 5. Repeated personal interactions between lobbyists and policymakers in the presence of asymmetric information, together with the resulting barriers to political entry, create private benefits for both citizens and lobbyists, and do not result in full private lobbying rent dissipation as is observed in the full information equilibrium.

The public's skeptical view of the close personal relationships between lobbyists and policymakers is hence only partially correct. Lobbyists do capture more rents than citizens. ${ }^{68}$ However, in absolute terms citizens are actually better off with this cronyism.

It is unsurprising that in a world of asymmetric information repeated relationships have the advantage of allowing the players to escape equilibria with unrealized opportunities to gain welfare enhancing information. What perhaps is surprising is the possibility that the quality of political decisions and the level of social welfare may be higher than found in the full information case when policymakers can observe lobbyists' actions and can extract all rents from them. Policymakers are self-interested and do not fully internalize all the benefits and costs of commercial lobbying activities (Groll and Ellis 2014). ${ }^{69}$ This is the standard result that introducing an extra distortion into a second-best world can be welfare improving. Here, it may be that the distortion introduced by the

\footnotetext{
${ }^{67}$ The private rent dissipation focuses on citizens' and lobbyists' private payoffs excluding spillover shares. The incomplete social rent dissipation arises because citizens and lobbyists do not internalize their spillover shares in their lobbying decisions. This result follows Groll and Ellis (2014) in a setting with observable verification efforts and signals and immediate, not promised, financial contributions. This is different to Cotton (2012) in which a policymaker extracts all rents from a wealthier interest group in a contributions-for-access environment whereas a less-wealthy interest group receives no access but enjoys private rents. The result shows that heterogeneous agents are not necessary for incomplete rent dissipation.

${ }^{68}$ Lessig (2011, pp. 117) points out: "[...] lobbyists get an ever-growing and increasing profitable business. The lobbying industry has exploded over the past twenty years. [...] And as the lobbying industry grows, D.C. gets rich, too. Nine of Washington's suburban counties are now listed by the Census Bureau as among the nation's twenty with the highest per capita income."

${ }^{69}$ Groll and Ellis (2014) identify several distortions in the full information market outcome: (i) each policymaker receives only a share of aggregate spillovers and does not internalize all benefits from improved policy information; (ii) each policymaker acts as a gate-keeper and can induce lobbying activities according to their preferences and payoffs, which follow form their trade-off between spillover improvements and financial contributions; and (iii) each policymaker does not bear any direct cost of lobbying activities. Following their Proposition 5 an underverification at the firm-level is more likely (i') the smaller the policymaker's share of expected aggregate spillovers (through a larger population T), (ii') the greater the policymakers' weight on financial contributions, whereas an oververification is more likely (iii') the greater the marginal processing costs.
} 
need to allow lobbyists information rents in an asymmetric information world offsets other distortions that induce oververification in a full information world.

The level of verification per firm induced by policymakers in the asymmetric information world is lower (Proposition 3) and there are fewer commercial lobbyists. ${ }^{70}$ Hence, if there is oververification at the firm-level in a full information world, then a policymaker's imperfect monitoring may improve social welfare outcomes. The welfare outcomes can be summarized as

Proposition 6. The social welfare effects of repeated commercial lobbying with asymmetric information are ambiguous. Further, asymmetric information may actually improve welfare outcomes in comparison to full information.

More generally, the welfare consequences of repeated personal interactions in a world of asymmetric information depend crucially on the attitude of the policymaker to solving the information and contracting problems, and the precision of the inferences the policymaker makes concerning lobbyists' unobservable verification effort. Alternatively expressed, they depend upon the trade-off between socially beneficial verification efforts and privately beneficial financial contributions.

Again, the public's skeptical view of the observed personal relationships between lobbyists and policymakers is only partially correct. In a world of asymmetric information repeated interactions facilitate socially valuable exchanges of information for political access. These repeated interactions also work to prevent policymakers from engaging in excessive rent extraction because they must share some of the rents with lobbyists and citizens to incent them to provide information and contributions. To summarize, asymmetric information can reduce distributional and social distortions arising from "well-intentioned but bad" policymakers, who would demand socially excessive information verification, and from "bad" policymakers, who have a strong preference for private rents.

\section{Conclusion and Discussions}

This study provides an explanation for the observed repeated personal interactions between lobbyists, special interests, and policymakers. Policymakers require repeated interactions both with commercial lobbyists and citizen-donors (special interest groups) so as to enforce implicit agency contracts. These contracts offer future political access in return for the delivery of promised financial contributions both by commercial lobbyists and citizen-donors and they similarly reward commercial

\footnotetext{
${ }^{70}$ The latter follows from the notion that the lobbyist's information rent reduces the marginal benefit of allocating access to a lobbyist rather than a citizen-donor (Proposition 4).
} 
lobbyists for delivering proposals of a given expected informational quality. In order for the promised access to provide these agents with the necessary incentives it must be the case that it yields them economic rents. Hence, the policymakers must create entry barriers (restrict political access) to prevent entry from competing these rents away. This creates the circumstances described elsewhere as cronyism. However, if commercial lobbying is socially desirable, then these repeated personal interactions between lobbyists and policymakers can improve social welfare outcomes. We show that the welfare implications depend on the policymakers' preferences and the efficacy of monitoring and of verification effort. Further, verification effort under asymmetric information is less than under full information. Somewhat surprisingly, welfare may be higher under imperfect information than under complete information if in the latter case policymakers would induce lobbying firms to engage in oververification relative to the first-best.

Our analysis speaks to some of the questions currently being explored in the empirical literature on lobbying. The crux of our argument is that policymaker time is the key scarce resource in this economy, and it is the control of this resource that allows policymakers to adopt the role of principals to their lobbyist-agents. This is exploited by policymakers by threatening to withhold future political access unless lobbyists perform today.

Our emphasis on the scarcity and importance of political access is consistent with empirical work on the revolving door phenomenon such as reported in Blanes i Vidal, Draca, and Fons-Rosen (2012) who show that lobbyists experience significant revenue losses when their previous work contact drops out of political office. ${ }^{71}$ While in our current analysis there is no mechanism for policymakers to lose office, it is clear that what is lost is the value of a repeated relationship. This point is also made by Krozner and Stratmann (1998) who provide evidence that repeated interactions allow policymakers and lobbyists to solve a contracting problem of promised campaign contributions for legislative favors. In our analysis we address this contracting problem, but recognize that lobbyists appear to be more than just "money-delivering" agents, and introduce the policymaker's information problem. ${ }^{72}$ Bertrand, Bombardini, and Trebbi (2014) address the empirical question whether lobbyists provide political access to their clients and employers or expertise to policymakers. They find stronger ev-

\footnotetext{
${ }^{71}$ The current regulation of federal lobbying activities (Lobbying Disclosure Act 1995 and amendments in 2006) does not allow direct identification of lobbyist-policymaker interactions as only client and lobbyist names are reported but not policymakers' names. Hence, recent empirical studies try to identify such networks by using common work history, party affiliation, or campaign contributions to link lobbyists and policymakers. For a discussion of the drawbacks of current lobbying disclosure rules for empirical work, and the difficulties with campaign contribution data see Mian, Sufi, and Trebbi (2013).

${ }^{72}$ It could be that lobbyists are "money-delivering" agents and that their formal expertise merely keeps up the appearance of information transmission. We leave this possibility to future research.
} 
idence for the former but cannot reject the latter. Our theoretical analysis is consistent with their empirical findings. Political access is the key scarce resource in our analysis and is used to incent lobbyists both to provide information and make financial contributions. We are mute on the question of why prior contacts determine initial political access as in the revolving door argument, but a simple additional transactions cost argument might explain this. It is cheaper in some sense to meet with someone whose attributes you already know.

Our model is the first to explain why there is simultaneous lobbying by both citizen-donors (special interest groups) and commercial lobbyists. This coexistence arises because citizen-donors can enjoy a comparative advantage in providing financial contributions, as they fully internalize the private benefits of their own proposals, while commercial lobbyists enjoy a comparative advantage in the provision of credible policy information information.

Our comparative statics results tell us that a decline in policymaker's time implies a growth in commercial lobbying both in terms of the number of commercial lobbyists and their revenues. This can explain the observed growth in commercial lobbying activities reported in Figure 1. It has been widely recognized and well documented that US Congress members have been required to spend an increasing proportion of their time on electoral campaigning and fundraising. Lessig (2011) reports that Congress members spend nowadays thirty to seventy percent of their work time in a given week fund raising because of the steadily increasing importance of politics over policies. Orstein, Mann and Malbin (2008) document that Congress members spend less time on legislation. Over, the last ten years the number of Congressional committee and subcommittee meetings as well as session days have significantly declined. Our model explains how commercial lobbyists benefit from increasingly busy policymakers by providing them with needed resources, and how policymakers rely more on those repeated lobbying partnerships to perform their own political tasks.

In some ways our analysis is relevant to the debate over transparency in the political process. Generally attention has focused on policymakers finances and the perceived need for campaign contribution limits. The obvious fear is that the transfer of resources purchases influence and causes distortions. The debate seems to largely neglect the transmission of information, which is actually desirable and justifies lobbying activities. Our analysis highlights that one may want to ask whether politicians meet with lobbyists to solve primarily a contracting or an information problem. For example, a disclosure of calendars and communication between lobbyists and policymakers might be informative in this context.

Our analysis also addresses the debate over the observed differences in financial political contri- 
butions in Europe and the USA. A policymaker's incentives to ask for a particular mix of socially beneficial information and privately beneficial resources for themselves may vary according to their political environment. One may argue, that relatively well-paid bureaucrats in Brussels who enjoy great job security, may value information and successful projects highly because of their own careerconcerns. Politicians in the United States, who face expensive electoral competition, may need more financial resources. Hence, the political structure and the implied incentives for policymakers, captured by $\alpha$ in our analysis, affect the observed mix of lobbying activities and therefore also the welfare outcomes.

Finally, and related to the last point, our analysis addresses the policymakers' preferences for contributions and information and the implications for lobbying activities. This raises interesting questions concerning the mix of lobbying activities over the electoral cycle where policymakers may experience a greater need for good policy results or greater financial contributions the closer is an election. We believe that the mechanisms by which lobbying activities and electoral campaigns complement each other and combine in creating value or distortions in policymaking process is intriguing and deserves further attention in the future.

\section{References}

[1] Ansolabehere, S., Figueiredo J. M. de, Snyder, J. M. (2003). Why Is There so Little Money in U.S. Politics, Journal of Economic Perspectives 17 (1), 105-130.

[2] Austen-Smith, D. (1994). Strategic Transmission of Costly Information, Econometrica 62 (4), 955-963.

[3] Austen-Smith, D. (1995). Campaign Contributions and Access, American Political Science Review 89 (3), 263-280.

[4] Austen-Smith, D. (1998). Allocating Access for Information and Contributions, Journal of Economics, Law and Organization 14 (2), 277-303.

[5] Baumgartner, F. R., Berry, J. M., Hojnacki, M., Kimball, D. C., Leech, B. L. (2009). Lobbying and Policy Change: Who Wins, Who Loses, and Why, University of Chicago Press: Chicago, IL.

[6] Becker, A. (2010). Multitudes of Lobbyists Weigh in on Dodd-Frank Act, The Washington Post November 22nd 2010.

[7] Bennedsen, M., Feldmann, S. E. (2002). Lobbying Legislatures, Journal of Political Economy 110 (4), 919-948.

[8] Bennedsen, M., Feldmann, S. E. (2006). Informational Lobbying and Political Contributions, Journal of Public Economics 90, 631-656. 
[9] Bernheim, B., D., Whinston, M. D. (1986). Menu Auctions, Resource Allocation, and Economic Influence, Quarterly Journal of Economics 101 (1), 1-31.

[10] Bertrand, M., Bombardini, M. and Trebbi, F. (2014). Is It Whom You Know or What You Know? An Empirical Assessment of the Lobbying Process, American Economic Review 104(12), pp. 3885-3920.

[11] Besley, T., Coate, S. (2001). Lobbying and Welfare in a Representative Democracy, Review of Economic Studies 68, 67-82.

[12] Black, D. A., Garen, J. E. (1991). Efficiency Wages and Equilibrium Wages, Economic Inquiry $29,525-540$.

[13] Blanes i Vidal, J., Draca, M., Fons-Rosen, C. (2012). Revolving Door Lobbyists, American Economic Review 102(7), pp. 3731-48.

[14] Center for Ethics in Government (2010). 50 State Chart: Contingency Fees, National Congress of State Legislators, updated June 2010. http://www.ncsl.org/Default.aspx?TabId=15351 (accessed May 2nd, 2011, pdf on hand).

[15] Chari, R., Hogan, J. and Murphy, G. (2010). Regulating Lobbying: A Global Comparison, Manchester University Press: Manchester, UK.

[16] Congleton, R. D., Hillman, A. L., Konrad, K. A. (2008). 40 Years of Research on Rent Seeking, vol. 1-2, Springer: Berlin, Germany.

[17] Cotton, C. (2009). Should We Tax or Cap Political Contributions? A Lobbying Model with policy favors and access. Journal of Public Economics 93, 831-842.

[18] Cotton, C. (2012). Pay-to-Play Politics: Informational Lobbying and Contribution Limits when Money Buys Access. Journal of Public Economics 96, 369-386.

[19] Crawford, V. P., Sobel, J. (1982). Strategic Information Transmission, Econometrica 50, 14311451.

[20] Dahm, M., Porteiro, N. (2008). Informational Lobbying under the Shadow of Political Pressure, Social Choice and Welfare 30 (4), 531-559.

[21] Dewatripont, M., Tirole, J. (1999). Advocates, Journal of Political Economy 107 (1), 1-39.

[22] Eisler, K. (2007). Hired Guns: The City's 50 Top Lobbyists, Washingtonian June 1st 2007.

[23] Esfahani, H. S., Salehi-Isfahani, D. (1989). Effort Observability and Worker Productivity: Towards an Explanation of Economic Dualism, Economic Journal 99, 818-836.

[24] Fahrmeir, L., Künstler, R., Pigeot, I., Tutz, G. (1997). Statistik, Springer: Berlin.

[25] Figueiredo, J. M. de, Richter, B. K. (2014). Advancing the Empirical Research on Lobbying, Annual Review of Political Science 17, 163185.

[26] Gilligan, T., Krehbiel, K. (1989). Asymmetric Information and Legislative Rules with a Heterogeneous Committee, American Political Science Review 33 (2), 459-490.

[27] Groll, T., Ellis, C. J. (2014). A Simple Model of the Commercial Lobbying Industry, European Economic Review 70, 299-316.

[28] Grossman, G., Helpman, E. (1994). Protection for Sale, American Economic Review 84 (4), 833-850.

[29] Grossman, G., Helpman, E. (1996). Electoral Competition and Special Interest Politics, Review of Economic Studies 63 (2), 265-286. 
[30] Grossman, G., Helpman, E. (2001). Special Interest Politics, MIT Press: Cambridge, MA.

[31] Hall, R. L., Deardorff, A. V. (2006). Lobbying as Legislative Subsidy, American Political Science Review 100 (1), 69-84.

[32] Hall, R. L., Wayman, F. (1990). Buying Time: Moneyed Interests and the Mobilization of Bias in Congressional Committees, American Political Science Review 84, 797-820.

[33] Hansen, J. M. (1991). Gaining Access: Congress and the Farm Lobby, 1919-1981, University of Chicago Press: Chicago, IL.

[34] Hirsch, A. V., Montagnes, B.P. (2015). The Lobbyist's Dilemma: Gatekeeping and the Profit Motive, mimeo.

[35] Hojnacki, M., Kimball, D. C. (2001). The Who and How of Organizations' Lobbying Contacts in Congressional Committees, Political Research Quarterly 54 (1), 161-180.

[36] Holmstrom, B. (1981). Contractual Models of the Labor Market, American Economic Review $71(2), 308-313$.

[37] House of Commons Public Administration Select Committee (2009). Lobbying: Access and influence in Whitehall - First Report of Session 2008-09, vol. 1, London UK.

[38] Jewitt, I. (1988). Justifying the First-Order Approach to Principal-Agent Problems, Econometrica 56 (5), 1177-1190.

[39] Kerr, W. R., William, F. L., Mishra, P. (2013). The Dynamics of Firm Lobbying, American Economic Journal: Economic Policy forthcoming.

[40] Krishna, V., Morgan, J. (2001). A Model of Expertise, Quarterly Journal of Economics 116 (2), 747-775.

[41] Kroszner, R. S., Stratmann, T. (1998). Interest-Group Competition and the Organization of Congress: Theory and Evidence from Financial Services' Political Action Committees, American Economic Review 88 (5), 1163-1187.

[42] Lessig, L. (2011). Republic, Lost: How Money Corrupts Congress and a Plan to Stop It. Twelve, Hachette Book Group: New York, NY.

[43] Levine, B. J. (2008). The Art of Lobbying: Building Trust and Selling Policy. CQ Press: Washington, D.C.

[44] Lohmann, S. (1995). Information Access and Contributions: A Signaling Model of Lobbying, Public Choice 85, 267-284.

[45] Mian, A., Sufi, A., Trebbi, F. (2013). The Political Economy of the Subprime Mortgage Credit Expansion, Quarterly Journal of Political Science 8, 373-408.

[46] Nownes, J. A. (2013). Interest Groups in American Politics: Pressure and Power, 2nd Edition, Routledge: New York, NY.

[47] Olson, M. (1965). The Logic of Collective Action: Public Goods and the Theory of Groups, Harvard University Press: Cambridge, MA.

[48] Orstein, N. J., Mann, Thomas E., Malbin, Michael J. (2008). Vital Statistics in Congress, Brookings Institution Press: Washington, DC.

[49] Persson, T., Tabellini, G. (2000). Political Economics: Explaining Economic Policy, MIT Press: Cambridge, MA.

[50] Potters, J., Winden, F. v. (1992). Lobbying and Asymmetric Information, Public Choice 74, 269-292. 
[51] Rogerson, W. P. (1985). The First-Order Approach to Principal-Agent Problems, Econometrica 53 (6), 1357-1367.

[52] Schmidt, S., Grimaldi, J. V. (2006). Abramoff Pleads Guilty to 3 Counts, The Washington Post January 4th 2006.

[53] The Senate Office for Public Records. Lobbying Disclosure Act Guidance, United States Senate, reviewed December 15th 2010.

[54] Shapiro, C., Stiglitz, J. E. (1984). Equilibrium Unemployment as a Worker Discipline Device, American Economic Review 74 (3), 433-444.

[55] Sparks, R. (1986). A Model of Involuntary Unemployment and Wage Rigidity: Worker Incentives and the Threat of Dismissal, Journal of Labor Economics 4 (4), 560-581.

[56] Tullock, G. (1980). Efficient Rent-Seeking, in: Buchanan, J. M., Tollison, R. D., Tullock, G. (eds), Toward a Theory of the Rent-Seeking Theory, Texas A\&M University Press, College Station, 97-112. 


\section{A Appendix}

\section{A.1 Proof of Proposition 1}

The statement follows from (2.18) and is independent of $\lambda_{t}^{l p}$ and $\mu_{t}^{l p}$ if $n_{t}^{l}>0$ and $\tilde{a}_{t}^{l p}>0$, which implies $m_{t}^{l p}>0$ if $D_{m}<0$ and $V^{l}>V^{c}$ because of $H^{\prime}(0)=0$.

\section{A.2 Proof of Lemma 1}

A citizen-donor with political access compares the payoffs of paying the current contribution and receiving future access with the payoff of not paying the current contribution and receiving no future access. In other, words the citizen-donor decides whether to be a citizen-donor in the future. The policymaker wants to maximize her payoff such that the citizen-donor's participation constraint is binding. Hence, we have

$$
\pi^{c}-\bar{f}_{t}^{c d}+\frac{V^{c} d}{1+r}=\pi^{c}+\frac{V^{c}}{1+r}
$$

which can be arranged to

$$
\bar{f}_{t}^{c d}=\frac{V^{c d}-V^{c}}{1+r}
$$

\section{A.3 Proof of Proposition 2}

All three statements of Proposition 2 follow immediately from (2.27) and (2.28) with

(i) $\frac{\partial \Pi^{p}}{\partial c^{p}}>\left.\frac{\partial \Pi^{p}}{\partial \tilde{a}^{l p}}\right|_{c^{p}=A^{p}, \sum_{l=1}^{l^{p}} \tilde{a}^{l p}=0}$ for the first statement, which implies a corner solution with $c^{p}=A^{p}$ and $\sum_{l=1}^{l^{p}} \tilde{a}^{l p}=0$

(ii) $\frac{\partial \Pi^{p}}{\partial c^{p}}<\left.\frac{\partial \Pi^{p}}{\partial \tilde{a}^{l_{p}}}\right|_{\sum_{l=1}^{l p} \tilde{a}^{l p}=A^{p}, c^{p}=0}$ for the second statement, which implies a corner solution with $c^{p}=0$ and $\sum_{l=1}^{l^{p}} \tilde{a}^{l p}=A^{p}$

(iii) $\frac{\partial \Pi^{p}}{\partial c^{p}}=\left.\frac{\partial \Pi^{p}}{\partial \tilde{a}^{l_{p}}}\right|_{c^{p}>0, \sum_{l=1}^{l^{p}} \tilde{a}^{l p}>0}$ for the third statement, which implies an interior solution with $c^{p}+$ $\sum_{l=1}^{l^{p}} \tilde{a}^{l p}=A^{p}, c^{p}>0$ and $\sum_{l=1}^{l^{p}} \tilde{a}^{l p}>0$

and describe the potential allocations of political access across citizen-donors and commercial lobbyists.

\section{A.4 Proof of Lemma 2}

For the interior solution with $m^{*}>0$ and $f^{*}>0$ we need that $V^{l}>V^{c}$, which follows from (2.18) and $f^{l *}=F($.$) .$

Applying $V^{l}>V^{c}$ to the lobbyist's contribution best-response $f^{l *}=F($.$) , it implies that \frac{\partial f^{l *}}{\partial \bar{q}^{l p}}=0$ as the lobbyist pays $f^{l *}=\bar{f}^{l p}$. Further, applying this to $\frac{\partial \Pi^{p}}{\partial \bar{q}^{p}}=0$ described in (2.29), it implies that $\frac{\partial m^{*}}{\partial \bar{q}^{l p}}=0$.

Applying $V^{l}>V^{c}$ to the lobbyist's contribution best-response $f^{l *}=F($.$) again, it also implies$ that $\frac{\partial f^{l *}}{\partial f^{l p}}=1$ as the lobbyist pays the increase. Applying this to $\frac{\partial \Pi^{p}}{\partial \bar{q}^{l p}}=0$ described in (2.30), we receive $\frac{\partial m^{*}}{\partial f^{l p}}<0$. Hence, the policymaker chooses a point on the lobbyist's incentive compatibility constraint. 
Quality Threshold Setting $\frac{\partial \Pi^{p}}{\partial \bar{q}^{l p}}=0$, which implies as described above that $\frac{\partial m^{*}}{\partial \bar{q}^{l p}}=0$, and employing (2.20), we have

$$
w\left(\epsilon^{*}\right) \frac{\phi}{\tilde{a}^{l p}}\left(V^{l}-V^{c}\right)+w^{\prime}\left(\epsilon^{*}\right) \partial V^{l} / \partial \bar{q}^{l p}=0 .
$$

Applying $\partial V^{l} / \partial \bar{q}^{l p}=-w\left(\epsilon^{*}\right)(r+D)^{-1}\left(V^{l}-V^{c}\right)$, we get

$$
w\left(\epsilon^{*}\right) \frac{\phi}{\tilde{a}^{l p}}\left(V^{l}-V^{c}\right)+w^{\prime}\left(\epsilon^{*}\right)\left(-w\left(\epsilon^{*}\right)(r+D)^{-1}\left(V^{l}-V^{c}\right)\right)=0,
$$

which reduces, because of $w^{\prime}\left(\epsilon^{*}\right)=w\left(\epsilon^{*}\right)(-\epsilon) / \sigma^{2}$ with $\sigma^{2}$ as the distribution's variance, to

$$
\frac{-\epsilon}{\sigma^{2}} \frac{\phi}{\tilde{a}^{l p}}=\frac{w\left(\epsilon^{*}\right)}{r+D}
$$

Because of $\epsilon<0$, we are on the left-hand side of the normal density function, which implies $w^{\prime}\left(\epsilon^{*}>0\right)$. This describes the global maximum of $\frac{\frac{\phi}{\alpha} w\left(\epsilon^{*}\right)}{r+D}$ and we denote this as $h^{*}$. Further, we define $\theta$ by $h^{*}=h(\theta)$. In equilibrium the optimal quality threshold is $\theta=\bar{q}-\phi m / \tilde{a}^{l p}$. We will employ this in the next step.

Verification Effort and Financial Contributions This step will describe the policymaker's trade-off between setting a quality threshold, which shall induce verification effort, and a financial contribution minimum, which shall induce contributions. Employing

$$
\frac{\partial m^{*}}{\partial \bar{f}^{l p}}=\frac{\partial \Pi_{m}^{l} / \partial \bar{f}^{l p}}{-\partial \Pi_{m}^{l} / \partial m^{l p}}=\frac{w\left(\epsilon^{*}\right) \frac{\phi}{\tilde{a}^{l p}}(1+r)^{-1} \frac{\partial V^{l}}{\partial \bar{f}^{l p}}}{H^{\prime \prime}(.)+\frac{\phi^{2}}{\tilde{a}^{2}} w^{\prime}\left(\epsilon^{*}\right) \frac{V^{l}-V^{c}}{1+r}}
$$

with

$$
\frac{\partial V^{l}}{\partial \bar{f}^{l p}}=-\frac{1+r}{r+D}
$$

we get

$$
\frac{\partial m^{*}}{\partial \bar{f}^{l p}}=-\frac{w\left(\epsilon^{*}\right) \frac{\phi}{\tilde{a}^{l p}}(r+D)^{-1}}{H^{\prime \prime}(.)+\frac{\phi^{2}}{\tilde{a}^{2}} w^{\prime}\left(\epsilon^{*}\right) \frac{V^{l}-V^{c}}{1+r}}<0
$$

Setting $\frac{\partial \Pi^{p}}{\partial f^{l p}}=0$ described in (2.30) and applying $\frac{\partial f^{l *}}{\partial f^{l p}}=1$ as well as (A.8), we have

$$
\alpha=\frac{s}{T} \psi \frac{w\left(\epsilon^{*}\right) \frac{\phi}{\tilde{a}^{l p}}(r+D)^{-1}}{H^{\prime \prime}(.)+\frac{\phi^{2}}{\tilde{a}^{2}} w^{\prime}\left(\epsilon^{*}\right) \frac{V^{l}-V^{c}}{1+r}} .
$$

Using the first-order condition from (2.18) for an interior solution, $u^{l p}>0$, we can write

$$
\alpha=\frac{s}{T} \psi \frac{w\left(\epsilon^{*}\right) \frac{\phi}{\tilde{a}^{l p}}(r+D)^{-1}}{H^{\prime \prime}(.)+\frac{\phi^{2}}{\tilde{a}^{2}} w^{\prime}\left(\epsilon^{*}\right)\left(H^{\prime}(.) \frac{\tilde{a}^{l p}}{\phi w\left(\epsilon^{*}\right)}\right)}=\frac{s}{T} \psi \frac{w\left(\epsilon^{*}\right) \frac{\phi}{\tilde{a}^{l p}}(r+D)^{-1}}{H^{\prime \prime}(.)+\frac{\phi}{\tilde{a}^{l p}} w^{\prime}\left(\epsilon^{*}\right) \frac{H^{\prime}(.)}{w\left(\epsilon^{*}\right)}} .
$$

Taking advantage of $w^{\prime}\left(\epsilon^{*}\right)=w\left(\epsilon^{*}\right)(-\epsilon) / \sigma^{2}$, we get

$$
\alpha=\frac{s}{T} \psi \frac{w\left(\epsilon^{*}\right) \frac{\phi}{\tilde{\tilde{a}}^{l p}}(r+D)^{-1}}{H^{\prime \prime}(.)+\frac{\phi}{\tilde{a}^{l p}}\left(w\left(\epsilon^{*}\right) \frac{-\epsilon}{\sigma^{2}}\right) \frac{H^{\prime}(.)}{w\left(\epsilon^{*}\right)}}=\frac{s}{T} \psi \frac{w\left(\epsilon^{*}\right) \frac{\phi}{\tilde{a}^{l p}}(r+D)^{-1}}{H^{\prime \prime}(.)+\frac{\phi}{\tilde{a}^{l p}}\left(\frac{-\epsilon}{\sigma^{2}}\right) H^{\prime}(.)} .
$$


From above we now that $(-\epsilon \phi) /\left(\sigma^{2} \tilde{a}^{l p}\right)=w\left(\epsilon^{*}\right)(r+D)^{-1}$ and therefore

$$
\alpha=\frac{s}{T} \psi \frac{w\left(\epsilon^{*}\right) \frac{\phi}{\tilde{a}^{l p}}(r+D)^{-1}}{H^{\prime \prime}(.)+\frac{w\left(\epsilon^{*}\right)}{r+D} H^{\prime}(.)},
$$

which can be rearranged to

$$
H^{\prime}(.)+H^{\prime \prime}(.) \frac{r+D}{w\left(\epsilon^{*}\right)}=\frac{s}{\alpha T}\left[\rho\left(s^{+} \mid x^{+}\right)-\rho\left(s^{-} \mid x^{+}\right)-\rho\left(s^{+}\right)+\rho\left(s^{-}\right)\right] \frac{\phi}{\tilde{a}^{l p}},
$$

where $0<\phi / \tilde{a}^{l p}<1$. The convexity of $H\left(\right.$.) ensures a unique solution to $m^{l p}$ together with the optimal $\bar{q}^{l p}$ from (A.5) and for a given $\tilde{a}^{l p}$, which we derive when we solve for the equilibrium.

The lobbyist's stationary first-order condition for verification effort can be derived from $\partial \Pi^{l} / \partial m^{l p}$, which is described in (2.18), and $\Pi^{l}=V^{l}$ such that

$$
H^{\prime}(.) \frac{r+D}{\frac{\phi}{\tilde{a}^{l p}} w\left(\epsilon^{*}\right)}=k n^{l}-G\left(n^{l}\right)-H\left(m^{l p}\right)-f^{l p}+\frac{r}{1+r} V^{c} .
$$

Tis can be rearranged for $\bar{f}^{l p}=f^{*}$, and using $h^{*}$ for the global maximum, to

$$
f^{l *}=k n^{l}-G\left(n^{l}\right)-\frac{r}{1+r} V^{c}-H\left(m^{l p}\right)-\frac{H^{\prime}\left(m^{l p}\right)}{h^{*}} .
$$

The solution to (A.5), (A.13), and (A.15) describes the joint solution to $\left\{\bar{q}^{l *}, m^{*}, \bar{f}^{l *}, f^{l *}\right\}$ given $\tilde{a}^{l p}$ and $V^{c}$.

\section{A.5 Proof of Proposition 3}

The first part of Proposition 3 articulates Lemma 2.

The second part of the proposition follows from the comparison with Proposition 2 in Groll and Ellis (2014). In their analysis for the full information case, where the policymaker can observe the lobbyist's information signal and effort, the interior solution with positive levels of verification and positive amounts of financial contributions can described by

$$
\frac{\partial H\left(m^{l}\right)}{\partial m^{l p}}=\rho\left(x^{+}\right) \frac{s}{\alpha T}\left[\rho\left(s^{+} \mid x^{+}\right)-\rho\left(s^{-} \mid x^{+}\right)-\rho\left(s^{+}\right)+\rho\left(s^{-}\right)\right] .
$$

Comparing (2.34) and (A.16), the terms of interest are $H^{\prime \prime}(.) \frac{r+D}{w\left(\epsilon^{*}\right)}>0$ and $0<\phi / \tilde{a}^{l p}<1$ which both imply that the verification effort per firm in the asymmetric information case is lower than in the full information case because of $H^{\prime}()>$.0 and $H^{\prime \prime}()>$.0 .

\section{A.6 Proof of Proposition 4}

The third statement of Proposition 2 provides

$$
\alpha \frac{\partial f^{c *}}{\partial c^{p}}-B^{\prime}\left(c^{p}+l^{p}\right)=\alpha \frac{\partial f^{l *}}{\partial \tilde{a}^{l p}}+\left.\frac{s}{T} \psi \frac{\partial m^{*}}{\partial \tilde{a}^{l p}}\right|_{0<\tilde{a}^{l p}<A^{p}} .
$$


Applying (2.8), $\frac{\partial f^{c *}}{\partial c^{p}}=\bar{f}^{c p}$ from Lemma 1, and $\frac{\partial f^{l *}}{\partial \tilde{a}^{l p}}=0$ from Appendix A.4, we can derive

$$
\alpha \bar{f}^{c}=\frac{s}{T} \rho\left(x^{+}\right)\left[\rho\left(s^{+} \mid x^{+}\right)-\rho\left(s^{-} \mid x^{+}\right)-\rho\left(s^{+}\right)+\rho\left(s^{-}\right)\right] \frac{\partial m^{*}}{\partial \tilde{a}^{l p}}+B^{\prime}\left(c^{p}+l^{p}\right) .
$$

\section{A.7 Proof of Lemma 3}

The symmetric steady state equilibrium to the interior solution to the policymaker's problem is described by 19 endogenous variables and 19 simultaneous equations without a recursive structure. ${ }^{73}$ The equilibrium conditions describing the agents' identity follow from the population constraint and symmetry for citizen-donors, lobbyists, and citizen-clients:

$$
\begin{aligned}
T & =\bar{P}+C^{d}+C^{-d}+L, \\
C^{d} & =c^{p} \bar{P}, \\
L & =l^{p} \bar{P} \\
\text { and } C^{-d} & =n^{l} L .
\end{aligned}
$$

The symmetric equilibrium conditions for the political access market follow from (2.4) and (2.17):

$$
\begin{aligned}
\frac{\tilde{a}^{l p}}{n^{l}} \pi^{c} & =k \\
\text { and } k & =G^{\prime}\left(n^{l}\right) .
\end{aligned}
$$

The lobbying labor market clears if

$$
e=\frac{D L}{C^{d}+C^{d}+n^{l} L} .
$$

The symmetric equilibrium conditions for the political access market follow the interior distribution of access, each lobbyist's presentation portfolio constraint, each lobbyist' client portfolio constraint, each lobbyists' incentive compatibility constraints, and each lobbyist's and citizen-donor's contribution constraint:

$$
\begin{aligned}
A^{p} & =c^{p}+l^{p} \tilde{a}^{l p} \\
\tilde{a}^{l p} & =\rho\left(x^{+}\right) m^{l p}+u^{l p} \\
n^{l} & =m^{l p}+u^{l p}+d^{l p} \\
\frac{-\epsilon}{\sigma^{2}} \frac{\phi}{\tilde{a}^{l p}} & =\frac{w\left(\epsilon^{*}\right)}{r+D} \\
H^{\prime}\left(m^{l p}\right)+H^{\prime \prime}\left(m^{l p}\right) \frac{r+D}{w\left(\epsilon^{*}\right)} & =\frac{1}{\alpha} \frac{s}{T} \rho\left(x^{+}\right)\left[\rho\left(s^{+} \mid x^{+}\right)-\rho\left(s^{-} \mid x^{+}\right)-\rho\left(s^{+}\right)+\rho\left(s^{-}\right)\right] \frac{\phi}{\tilde{a}^{l p}}, \\
\alpha \bar{f}^{c}-B^{\prime}\left(c^{p}+l^{p}\right) & =\frac{s}{T} \rho\left(x^{+}\right)\left[\rho\left(s^{+} \mid x^{+}\right)-\rho\left(s^{-} \mid x^{+}\right)-\rho\left(s^{+}\right)+\rho\left(s^{-}\right)\right] \frac{\partial m^{*}}{\partial \tilde{a}^{l p}}, \\
\bar{f}^{l p}=f^{l p} & =k n^{l}-G\left(n^{l}\right)-\frac{r}{1+r} V^{c}-H\left(m^{l p}\right)-\frac{H^{\prime}\left(m^{l p}\right)}{h^{*}},
\end{aligned}
$$

\footnotetext{
${ }^{73}$ This differs to Groll and Ellis $(2013,2014)$ where commercial lobbyists crowd out citizens and are the only ones who gain political access. Their setting allows to solve the system of equilibrium equations with its recursive structure.
} 


$$
\bar{f}^{c p}=f^{c p}=\frac{V^{c d}-V^{c}}{1+r} .
$$

The symmetric equilibrium payoffs for lobbyists, citizen-clients, and citizen-donors are:

$$
\begin{aligned}
V^{l} & =\left(\frac{1+r}{r}\right)\left(\frac{r+e}{1-e}\right) \frac{H^{\prime}\left(m^{l p}\right)}{h^{*}}>0, \\
V^{c} & =\frac{(1+r) e}{r+e} V^{l}>0, \\
V^{c d} & =\pi^{c}+\frac{V^{c}}{1+r}>0 .
\end{aligned}
$$

The determinant of the system above and its Jacobian matrix without $D^{*}=D\left(\bar{q}^{l p}, \tilde{a}^{l p}, m^{l p}\right)$ is

$$
\operatorname{Det}[J]=\frac{\bar{P}\left(\tilde{a}^{l p}-n^{l}-1\right) H^{\prime}(.)\left(\tilde{a}^{l p} \pi^{c}+n^{l 2} G^{\prime \prime}(.)\right)\left(\left(m^{l p}-\phi\right) H^{\prime \prime}(.)+H^{\prime}(.)\right)\left(H^{\prime \prime \prime}(.)\left(r+D+H^{\prime \prime}(.) D^{\prime}(.)\right)\right)\left(D^{\prime \prime}(.)(D+r)-D^{\prime}(.)^{2}\right)}{\tilde{a}^{l p} n^{l 2}(r+D)\left(H^{\prime \prime}\left(m^{l p}\right)(D+r)+H^{\prime}\left(m^{l p}\right) D^{\prime}\left(\bar{q}^{l p}-\frac{m^{l p} \tilde{a}^{l}}{\tilde{a}^{l p}}\right)\right)^{2}} \neq 0
$$

because of the properties of the cost functions and Assumption 1. The derivation and all comparative statics illustrated in Table 2 can be found in the supplemental Mathematica notebooks.

\section{A.8 Proof of Proposition 5}

Proposition 1, (3.4), (3.5), and (3.6) imply that $V^{l *}>V^{c d *}>V^{c *}>0$. The second part of the statement follows from the comparison to the full information outcome in which policymakers can observe the lobbyists' information efforts and signals. In the full information market outcome the rent distribution follows.

Lemma 3 (Groll and Ellis, 2014). In the market equilibrium policymakers extract all expected private rents from citizens and commercial lobbying firms.

Their statement implies that in the full information market outcome we have $V^{l}=V^{c}=0$, which generates less private rents than $V^{l *}>V^{c d *}>V^{c *}>0$.

\section{A.9 Proof of Proposition 6}

We reverse the order. The second part of the statement follows from a combination of Proposition 3 in Groll and Ellis (2014) and Proposition 3.

Proposition 3 (Groll and Ellis, 2014). Comparing the verification effort levels at the full information social welfare optimum and the full information market outcome, we have

$$
\alpha T-\left[\left.\frac{\partial G\left(n^{l}\right)}{\partial n^{l}}\right|_{n^{l}=m^{*}} /\left.\frac{\partial H\left(m^{l}\right)}{\partial m^{l}}\right|_{m^{l}=m^{* *}}\right] \gtreqless 1 \Rightarrow m^{*} \gtreqless m^{* *} .
$$

The proposition states that if there is an oververification, $m^{*}<m^{* *}$, or an underverification, $m^{*}>m^{* *}$, at the firm-level in the market outcome compared to the social optimum, then the full information market outcome is not socially efficient. Suppose that there is an underverification at the firm-level with full information. Asymmetric information would reduce verification efforts 
(Proposition 2) and worsen social outcomes. Now suppose there is an oververification at the firmlevel with full information. Here asymmetric information would reduce the oververification and improve social outcomes.

Now for the first statement we use the argumentation of the second statement and a comparison of repeated commercial lobbying to one-shot interactions. Repeated interactions are necessary for informational commercial lobbying (Proposition 1) and improve the expected quality of spillovers and may increase social welfare. However, commercial lobbyists may also deliver socially undesirable financial contributions and policymakers may request too much verification efforts per firm. If the full information market outcome exhibits underverification at the firm level, given that the number of commercial lobbyists is the same in both scenarios, then the asymmetric information market outcome is socially inefficient and actually worsens outcomes further. If the full information outcome exhibits oververification at the firm level, then asymmetric information can offset the distortions (market power and cost and spillover externalities) and improve social outcomes and may result in a socially efficient outcome. 


\section{B Supplemental Appendix: Online}

\section{B.1 Descriptive Statistics: Lobbying Firms}

Table 3: Summary Statistics Lobbying Firms - U.S. Federal Lobbying 2010

\begin{tabular}{lccccc}
\hline \multicolumn{1}{c}{ Variable } & Mean & Std. Dev. & Min. & Max. & Median \\
\hline Employees & 6.324 & 18.125 & 1 & 244 & 2 \\
$\quad$ In DC-Area & 5.523 & 17.53 & 0 & 241 & 1 \\
$\quad$ Outside DC-Area & 0.802 & 2.861 & 0 & 56 & 0 \\
Clients & 9.259 & 18.132 & 1 & 252 & 4 \\
Issue Categories & 5.45 & 7.414 & 0 & 56 & 3 \\
Revenues in Current $\$ 1,000$ & 670.288 & 1825.562 & 5 & 27,060 & 154.5 \\
Alumni Lobbyists & 0.482 & 1.304 & 0 & 16 & 0 \\
Current Congress Members Served & 0.553 & 1.544 & 0 & 19 & 0 \\
N=1613 & & & & & \\
\hline
\end{tabular}

Data are from Lobbyists.info: "Factors of Influence", updated Feb 5 2013, Aug 14 2013. Sample of entries with revenue entries and positive employees. The Lobbying Disclosure Code specifies 79 issue codes such as, for example, Accounting, Advertising, Health Issues, Housing, Tobacco, or Tourism. Alumni Lobbyist is the number of lobbyists in a firm who have worked for any current Congress members; Current Congress Members served describes the unique of number of Congress members for whom a firm's overall alumni lobbyists have worked for during their career.

\section{B.2 Corner Solution: Direct Lobbying Only}

Suppose $\frac{\partial \Pi^{p}}{\partial \tilde{a}^{p}}<\left.\frac{\partial \Pi^{p}}{\partial c^{p}}\right|_{A^{p}=c^{p}}$ for the policymaker's problem described in (2.25). All political access is allocated by each policymaker to citizen-donors and there is no access for commercial lobbyists.

Equilibrium The full symmetric steady state equilibrium for this corner solution is characterized by the following equilibrium conditions as well as the population constraint, adding-up conditions, access rules, and a formal description of the asset value equations incorporating the lobbyists' choices.

$$
\begin{aligned}
\text { Market for Political Access: } & A_{t}=\bar{P} A^{p}, c_{t}^{p}=A_{t}^{p}, \text { and } \tilde{a}_{t}^{l p}=0 . \\
\text { Lobbying Labor Market: } & \text { not existent because of } \tilde{a}_{t}^{l p}=l_{t}^{p}=0 . \\
\text { Market for Lobbying Services: } & \text { not existent because of } \tilde{a}_{t}^{l p}=l_{t}^{p}=0 .
\end{aligned}
$$

The equilibrium conditions imply that all endogenous variables describing the outcomes in the lobbying labor market and market for lobbying services are equal to zero and only the market for political access is existent.

Focusing on the market for political access and updating the population constraint, $T=C_{t}+$ $L_{t}+\bar{P}$, we have

$$
T=C_{t}^{-d}+C_{t}^{d}+\bar{P}
$$

where $C^{*}=C^{-d *}+C^{d *}=T-\bar{P}$ and $L^{*}=0$, and using (B.1), we have $C^{d *}=\bar{P} c^{p}=\bar{P} A^{p}$, which implies $C^{-d *}=T-\bar{P}\left(1+A^{p}\right)$. The values for $\left\{C^{*}, C^{-d *}, C^{d *}, L^{*}\right\}$ describe the identity of agents.

Focusing on the financial contribution values and citizens' payoffs, we can apply Lemma 1 and 
the citizen-donors' stationary participation constraint. The stationary citizen-donor payoff is

$$
V^{c d}=\frac{1+r}{r}\left(\pi^{c}-\bar{f}^{c p}\right)
$$

such that $V^{c d}-V^{c}$ can be written as $\frac{1+r}{r}\left(\pi^{c}-\bar{f}^{c p}\right)-V^{c}$. Applying $\bar{f}_{t}^{c p}=\frac{V^{c d}-V^{c}}{1+r}$, we have

$$
\frac{1+r}{r}\left(\pi^{c}-\bar{f}^{c p}\right)-V^{c}=(1+r) \bar{f}^{c p}
$$

Because of no entry into the political access market, we can apply $V^{c}=0$. This implies

$$
\bar{f}^{c *}=f^{c *}=\frac{\pi^{c}}{1+r}>0
$$

and expected private steady state payoffs of

$$
V^{c *}=0 \text { and } V^{c d *}=(1+r) \bar{f}^{c *}=\pi^{c}>0
$$

for citizens and citizen-donors. The values for $\left\{\bar{f}^{c *}, f^{c *}, V^{c *}, V^{c d *}\right\}$ together with $\left\{C^{*}, C^{-d *}, C^{d *}, L^{*}\right\}$ describe the full symmetric steady state equilibrium here.

\section{B.3 Corner Solution: Specialization in Lobbying with Contributions and Infor- mation}

Suppose $\frac{\partial \Pi^{p}}{\partial \tilde{a}^{l p}}=\left.\frac{\partial \Pi^{p}}{\partial c^{p}}\right|_{A^{p}=c^{p}+l^{p} \tilde{a}^{l p}},\left.\frac{\partial \Pi^{p}}{\partial \bar{q}^{l p}}\right|_{\bar{q}^{l p}>0}=0$, and $\left.\frac{\partial \Pi^{p}}{\partial f^{l p}}\right|_{\bar{f}^{l p}=0} \leq 0$ for the policymaker's problem described in (2.25). All political access is allocated by each policymaker to citizen-donors and commercial lobbyists but there is no expectation for contributions by commercial lobbyists.

Equilibrium The full symmetric steady state equilibrium for this corner solution is characterized by the following equilibrium conditions as well as the population constraint, adding-up conditions, access rules, and a formal description of the asset value equations incorporating the lobbyists' choices.

$$
\begin{aligned}
\text { Market for Political Access: } & A_{t}=\bar{P} A^{p}, A_{t}^{p}=c_{t}^{p}+l_{t}^{p} \tilde{a}_{t}^{l p}, c_{t}^{p}>0, l_{t}^{p}>0, \text { and } \tilde{a}_{t}^{l p}>0 . \\
\text { Lobbying Labor Market: } & e_{t}\left(C_{t}+D_{t} L_{t}\right)=D_{t} L_{t} . \\
\text { Market for Lobbying Services: } & G^{\prime}\left(n_{t}^{l}\right)=k_{t}=\frac{\tilde{a}_{t}^{l p}}{n_{t}^{l}} \pi^{c} \text { for all } l \text { and } t .
\end{aligned}
$$

The equilibrium conditions imply that there is no demand for contributions by commercial lobbyists and lobbyists to exhibit a maximum of verification efforts - i.e., $\bar{f}^{l *}=f^{l *}=0$.

The remainder of the symmetric steady state equilibrium is described by the following simultaneous equations without a recursive structure. The equilibrium conditions describing the agents' identity follow from the population constraint and symmetry for citizen-donors, lobbyists, and citizenclients:

$$
\begin{aligned}
T & =\bar{P}+C^{d}+C^{-d}+L, \\
C^{d} & =c^{p} \bar{P},
\end{aligned}
$$




$$
\begin{aligned}
L & =l^{p} \bar{P} \\
\text { and } C^{-d} & =n^{l} L .
\end{aligned}
$$

The symmetric equilibrium conditions for the political access market follow from (2.4) and (2.17):

$$
\begin{aligned}
& \frac{\tilde{a}^{l p}}{n^{l}} \pi^{c}=k \\
& \text { and } k=G^{\prime}\left(n^{l}\right) .
\end{aligned}
$$

The lobbying labor market clears if

$$
e=\frac{D L}{C^{d}+C^{d}+n^{l} L} .
$$

The symmetric equilibrium conditions for the political access market follow the interior distribution of access, each lobbyist's presentation portfolio constraint, each lobbyist' client portfolio constraint, each lobbyists' incentive compatibility constraints, and each lobbyist's and citizen-donor's contribution constraint:

$$
\begin{aligned}
A^{p} & =c^{p}+l^{p} \tilde{a}^{l p}, \\
\tilde{a}^{l p} & =\rho\left(x^{+}\right) m^{l p}+u^{l p}, \\
\frac{n}{n^{2}} \frac{\phi}{\tilde{a}^{l p}} & =\frac{w\left(\epsilon^{*}\right)}{r+D}, \\
H^{\prime}\left(m^{l p}\right)+H^{\prime \prime}\left(m^{l p}\right) \frac{r+D}{w\left(\epsilon^{*}\right)} & =\frac{1}{\alpha} \frac{s}{T} \rho\left(x^{+}\right)\left[\rho\left(s^{+} \mid x^{+}\right)-\rho\left(s^{-} \mid x^{+}\right)-\rho\left(s^{+}\right)+\rho\left(s^{-}\right)\right] \frac{\phi}{\tilde{a}^{l p}}, \\
\alpha \bar{f}^{c}-B^{\prime}\left(c^{p}+l^{p}\right) & =\frac{s}{T} \rho\left(x^{+}\right)\left[\rho\left(s^{+} \mid x^{+}\right)-\rho\left(s^{-} \mid x^{+}\right)-\rho\left(s^{+}\right)+\rho\left(s^{-}\right)\right] \frac{\partial m^{*}}{\partial \tilde{a}^{l p}}, \\
\bar{f}^{c p}=f^{c p} & =\frac{V^{c d}-V^{c}}{1+r} .
\end{aligned}
$$

The symmetric equilibrium payoffs for lobbyists, citizen-clients, and citizen-donors are:

$$
\begin{aligned}
V^{l} & =\left(\frac{1+r}{r}\right)\left(\frac{r+e}{1-e}\right) \frac{H^{\prime}\left(m^{l p}\right)}{h^{*}}>0, \\
V^{c} & =\frac{(1+r) e}{r+e} V^{l}>0, \\
V^{c d} & =\pi^{c}+\frac{V^{c}}{1+r}>0 .
\end{aligned}
$$

\section{B.4 Corner Solution: Specialization in Lobbying with Contributions}

Suppose $\frac{\partial \Pi^{p}}{\partial \tilde{a}^{l p}}=\left.\frac{\partial \Pi^{p}}{\partial c^{p}}\right|_{A^{p}=c^{p}+l^{p} \tilde{a}^{l p}},\left.\frac{\partial \Pi^{p}}{\partial \bar{q}^{l p}}\right|_{\bar{q}^{l p}=0} \leq 0$, and $\left.\frac{\partial \Pi^{p}}{\partial f^{l p}}\right|_{\bar{f}^{l p}>0} \geq 0$ for the policymaker's problem described in (2.25). All political access is allocated by each policymaker to citizen-donors and commercial lobbyists but there is no expectation for verification effort.

Equilibrium The full symmetric steady state equilibrium for this corner solution is characterized by the following equilibrium conditions as well as the population constraint, adding-up conditions, 
access rules, and a formal description of the asset value equations incorporating the lobbyists' choices.

$$
\begin{aligned}
\text { Market for Political Access: } & A_{t}=\bar{P} A^{p}, A_{t}^{p}=c_{t}^{p}+l_{t}^{p} \tilde{a}_{t}^{l p}, c_{t}^{p}>0, l_{t}^{p}>0, \text { and } \tilde{a}_{t}^{l p}>0(\mathrm{~B} .29) \\
\text { Lobbying Labor Market: } & L_{t}>0 \text { but } e_{t}=0 . \\
\text { Market for Lobbying Services: } & G^{\prime}\left(n_{t}^{l}\right)=k_{t}=\frac{\tilde{a}_{t}^{l p}}{n_{t}^{l}} \pi^{c} \text { for all } l \text { and } t .
\end{aligned}
$$

The equilibrium conditions imply that there is no demand for verification efforts, no entry into the lobbying industry, and no positive rents for citizen-clients - i.e., $\bar{q}^{*}=m^{*}=D^{*}=e^{*}=V^{c *}=0$.

The remaining endogenous variables are explained is described by the following simultaneous equations without a recursive structure. The equilibrium conditions describing the agents' identity follow from the population constraint and symmetry for citizen-donors, lobbyists, and citizen-clients:

$$
\begin{aligned}
T & =\bar{P}+C^{d}+C^{-d}+L, \\
C^{d} & =c^{p} \bar{P}, \\
L & =l^{p} \bar{P} \\
\text { and } C^{-d} & =n^{l} L .
\end{aligned}
$$

The symmetric equilibrium conditions for the political access market follow from (2.4) and (2.17):

$$
\begin{aligned}
\frac{\tilde{a}^{l p}}{n^{l}} \pi^{c} & =k \\
\text { and } k & =G^{\prime}\left(n^{l}\right) .
\end{aligned}
$$

There is no lobbying labor market, and the symmetric equilibrium conditions for the political access market follow each lobbyist's presentation portfolio constraint, each lobbyist' client portfolio constraint, each lobbyists' incentive compatibility constraints with $m^{*}$, and each lobbyist's and citizen-donor's contribution constraint:

$$
\begin{aligned}
A^{p} & =c^{p}+l^{p} \tilde{a}^{l p}, \\
\tilde{a}^{l p} & =u^{l p}, \\
n^{l} & =u^{l p}+d^{l p}, \\
\alpha \frac{\pi^{c}}{1+r} & =B^{\prime}\left(c^{p}+l^{p}\right), \\
\bar{f}^{l *}=f^{l *} & =\frac{k n^{l}-G\left(n^{l}\right)}{1+r}, \\
\bar{f}^{c *}=f^{c *} & =\frac{V^{c d}-V^{c}}{1+r}=\frac{\pi^{c}}{1+r} .
\end{aligned}
$$

The symmetric equilibrium payoffs for lobbyists, citizen-clients, and citizen-donors are:

$$
\begin{gathered}
V^{l *}=\frac{(1+r)\left(r+e^{*}\right)}{r\left(1-e^{*}\right)} \frac{H^{\prime}\left(m^{*}\right)}{\frac{\phi}{\tilde{a}^{*}} w\left(\epsilon^{*}\right)}, \\
V^{c *}=\frac{(1+r) e^{*}}{r+e^{*}} V^{l *}>0
\end{gathered}
$$




$$
V^{c d}=\pi^{c}+\frac{V^{c *}}{1+r}>0
$$

\section{B.5 Corner Solution: Commercial Lobbying with Verification Efforts}

Suppose $\frac{\partial \Pi^{p}}{\partial \tilde{a}^{l p}}>\left.\frac{\partial \Pi^{p}}{\partial c^{p}}\right|_{\sum_{l=1}^{l^{p}} \tilde{a}^{l p}=A^{p}}$ for the policymaker's problem described in (2.25). All political access is allocated by each policymaker to commercial lobbyists and there is no access for citizen-donors.

Equilibrium The full symmetric steady state equilibrium for this corner solution is characterized by the following equilibrium conditions as well as the population constraint, adding-up conditions, access rules, and a formal description of the asset value equations incorporating the lobbyists' choices.

$$
\begin{aligned}
\text { Market for Political Access: } & A_{t}=\bar{P} A^{p}, c_{t}^{p}=0, \text { and } \sum_{l=1}^{l^{p}} \tilde{a}_{t}^{l p}=A^{p} . \\
\text { Lobbying Labor Market: } & e_{t}\left(C_{t}+D_{t} L_{t}\right)=D_{t} L_{t} . \\
\text { Market for Lobbying Services: } & G^{\prime}\left(n_{t}^{l}\right)=k_{t}=\frac{\tilde{a}_{t}^{l p}}{n_{t}^{l}} \pi^{c} \text { for all } l \text { and } t .
\end{aligned}
$$

The equilibrium conditions imply that all endogenous variables describing citizen-donors and their potential activities are zero - i.e., $C^{d *}=\bar{f}^{c *}=f^{c *}=V^{c d *}=0$ and $C^{-d *}=C^{*}$.

In a corner solution to the policymaker's optimization described in (2.25) with only verification effort by commercial lobbyists, each policymaker sets $\tilde{a}^{c p}=0$ such that $c^{p}=0$ and $\bar{f}^{l p}=0$ to extract lobbyists' available resources via verification efforts by adjusting the information quality threshold. Note that a lobbyist who would make a positive financial contribution would be dropped as a contribution would reduce resources for verification. So a lobbyist's best-response is $f^{l *}=0$. The first-order condition for the quality threshold is

$$
\frac{\partial \Pi^{p}}{\partial \bar{q}^{l p}}=\frac{\rho\left(x^{+}\right) s}{\alpha T}\left[\rho\left(s^{+} \mid x^{+}\right)-\rho\left(s^{-} \mid x^{+}\right)-\rho\left(s^{+}\right)+\rho\left(s^{-}\right)\right] \frac{\partial m^{*}}{\bar{q}^{l p}},
$$

which again implies $\frac{\partial m^{*}}{\bar{q}^{l p}}=$ for $\bar{q}^{l p}>0$. This implies that

$$
\frac{-\epsilon}{\sigma^{2}} \frac{\phi}{\tilde{a}}=\frac{w\left(\epsilon^{*}\right)}{r+D}
$$

It follows that a policymaker chooses $\bar{q}^{l p}$ to solve (B.51). Again, at low levels of $\bar{q}^{l p}$ an increase in this minimum quality requirement increases verification, whereas for $\bar{q}^{l p}$ sufficiently high an increase in this minimum quality requirement decreases verification. It follows that (B.51) displays a global maximum. Using (B.51) and the lobbyist's stationary first-order condition from (A.14), the corresponding $m^{*}$ solves

$$
H\left(m^{l}\right)+H^{\prime}\left(m^{l}\right) \frac{r+D}{\frac{\phi}{\tilde{a}} w\left(\epsilon^{*}\right)}=k n^{l}-G\left(n^{l}\right)-\frac{r V^{c}}{1+r}
$$

and is unique because of the convexity of $H($.$) .$ 
Equilibrium To obtain the equilibrium values for the variables in the model we are able to exploit the problem's recursive structure. We first solve for $n^{*}$. Then using $n^{*}$ we obtain $k^{*}, L^{*}$, and $C^{*}$ from the lobbying services market. Next we use these values to describe the equilibrium in the political access market and finally in the lobbying labor market.

From the population constraint and because of $C_{t}=L_{t} n_{t}^{l}$ we may write

$$
L_{t}=\frac{T-\bar{P}}{1+n_{t}^{l}} .
$$

From the equilibrium condition in the political access market, (B.47), and the equilibrium in the lobbying service market, (B.49), we have

$$
\frac{\bar{P} A^{p}}{L_{t} n_{t}^{l}} \pi^{c}=G^{\prime}\left(n_{t}^{l}\right) \text { for every } l \text { and } t .
$$

Using (B.53) and (B.54), the implicit solution for the equilibrium number of clients per firm follows from

$$
\left.\frac{n^{*}}{1+n^{*}} G^{\prime}\left(n_{t}^{l}\right)\right|_{n^{l}=n^{*}}=\frac{\bar{P} A^{p} \pi^{c}}{T-\bar{P}}
$$

where the equilibrium number of clients is positive and unique. ${ }^{74}$ The equilibrium numbers of lobbyists and citizens are then

$$
L^{*}=\frac{T-\bar{P}}{1+n^{*}} \text { and } C^{*}=L^{*} n^{*}
$$

and the equilibrium lobbying service fee is

$$
k^{*}=\left.G^{\prime}\left(n_{t}^{l}\right)\right|_{n^{l}=n^{*}} .
$$

The market clearing lobbying service fee thus depends on the number of clients, lobbyists' political access, the private benefit of an enacted policy proposal, and the cost of processing proposals. The values of $k^{*}, n^{*}, L^{*}$, and $C^{*}$ describe the equilibrium in the lobbying service market.

Continuing with the market on which lobbyists and policymakers trade for political access and applying (B.47), each lobbying firm receives political access of

$$
\tilde{a}^{*}=\frac{\bar{P} A^{p}}{L^{*}}
$$

in exchange for their lobbying efforts. Each policymaker sets $\bar{f}^{l p}=0$ and maximizes the resources available for verification efforts. Lobbyists make no financial contributions, $\bar{f}^{l *}=f^{l *}=0$, because it would signal a waste of resources. The equilibrium quality threshold and verification effort follow (B.51) and (B.52) for a given $V^{c}$. The steady state entry into the lobbying industry follows from B.48 and B.56 such that $e=\frac{D}{n+D}$.

The value asset equation for a citizen follows from (B.48) and it holds that there is a private rent dissipation for citizens in the current period as characterized by (B.54) and (B.57) - i.e., $\Pi_{t}^{c}=0$.

\footnotetext{
${ }^{74}$ See Groll and Ellis (2014).
} 
Hence, we have

$$
V^{c}=\frac{(1+r) e}{r+e} V^{l}
$$

Finally, the value asset equation for a lobbyist without financial contributions can be written as

$$
V^{l}=\frac{(1+r)\left(k n-G(n)-H\left(m^{l p}\right)\right)}{r+D}+\frac{D}{r+D} V^{c} .
$$

Using (B.59) and (B.60), we get

$$
V^{l}=\frac{(1+r)\left(k n^{l}-G\left(n^{l}\right)-H\left(m^{l p}\right)\right)\left(r+e^{*}\right)}{r(r+e+D(1-e))} .
$$

Using (B.52) and (B.59), we have

$$
H\left(m^{l}\right)+H^{\prime}\left(m^{l}\right) \frac{r+D}{\frac{\phi}{\tilde{a}} w\left(\epsilon^{*}\right)}=k n^{l}-G\left(n^{l}\right)-\frac{r e}{r+e} V^{l}
$$

Using $e=\frac{D}{n^{*}+D},(\mathrm{~B} .61)$, and (B.62), we can write

$$
H^{\prime}\left(m^{l p}\right) \frac{1}{\frac{\phi}{\tilde{a}} w\left(\epsilon^{*}\right)}=\left(k n^{*}-G\left(n^{*}\right)-H\left(m^{l p}\right)\right) \frac{n^{*}}{r\left(n^{*}+D\right)+D\left(1+n^{*}\right)}
$$

which solves with (B.51) and $\tilde{a}^{*}$ for $\left\{\bar{q}^{*}, m^{*}\right\}$ that is unique as shown. The pair $\left\{\bar{q}^{*}, m^{*}\right\}$ solve for $D^{*}$, which solves for $e^{*}$. The expected lifetime payoff for a lobbyist in steady state is then

$$
V^{l *}=\frac{(1+r)\left(r+e^{*}\right)}{r\left(1-e^{*}\right)} \frac{H^{\prime}\left(m^{*}\right)}{\frac{\phi}{\tilde{a}^{*}} w\left(\epsilon^{*}\right)}
$$

and for a citizen

$$
V^{c *}=\frac{(1+r) e^{*}}{r+e^{*}} V^{l *}>0 .
$$

Finally, $u^{*}=\tilde{a}^{*}-\rho\left(x^{+}\right) m^{*}$ and $d^{*}=n^{*}-m^{*}-u^{*}$. 